Towards computer-assisted diagnosis of precursor colorectal lesions

Entwicklung von Methoden zur Computer-assistierten Diagnose von Vorstufen kolorektaler Läsionen

Institut für Pathologie

Universitätsklinikum Erlangen

\author{
Der Medizinischen Fakultät \\ der Friedrich-Alexander-Universität \\ Erlangen-Nürnberg \\ zur \\ Erlangung des Doktorgrades Dr. med.
}

vorgelegt von

Claudia Dach

aus Mainz 
Als Dissertation genehmigt von der Medizinischen Fakultät

der Friedrich-Alexander-Universität Erlangen-Nürnberg

Tag der mündlichen Prüfung: 22. Januar 2019

Vorsitzender des Promotionsorgans: Prof. Dr. Dr. h.c. Jürgen Schüttler

Gutachter: Prof. Dr. Arndt Hartmann

Prof. Dr. Maximilian Waldner 


\section{Table of Content}

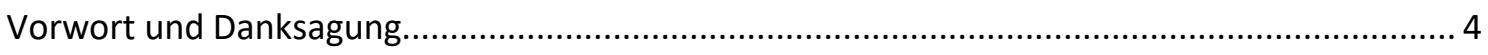

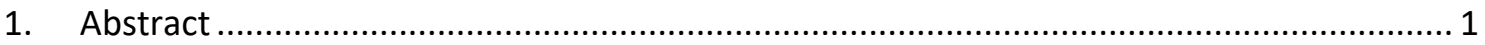

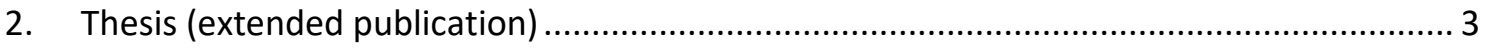

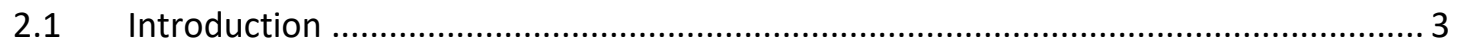

2.1.1. Precursor colorectal lesions: Is computer-assisted diagnosis useful? .................. 3

2.1.2. Digital Pathology: Past to Present.................................................................... 5

2.1.3. Digital Pathology: Image Analysis and its application ......................................... 8

2.1.4. Aim of this study: Image Analysis of precursor colorectal lesions ...................... 13

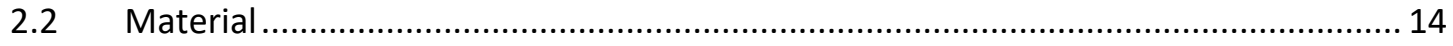

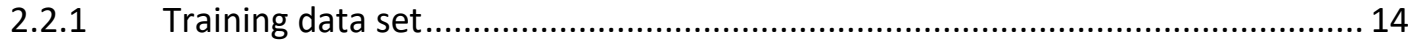

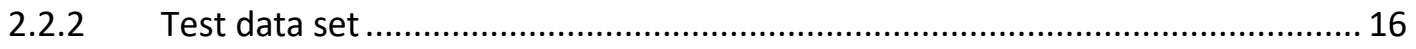

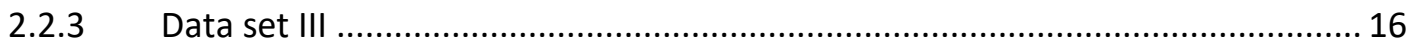

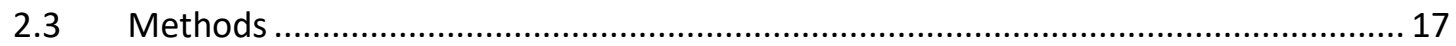

2.3.1 Description of serration with geometric features............................................ 17

2.3.2 Description of cytological dysplasia with histogram-based features.................. 19

2.3.3 Cut-offs for serration and cytological dysplasia ................................................. 21

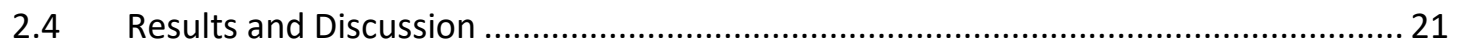

2.4.1 Suitable geometric features for describing serration ........................................ 21

2.4.2 Suitable histogram-based features for describing cytological dysplasia ............. 23

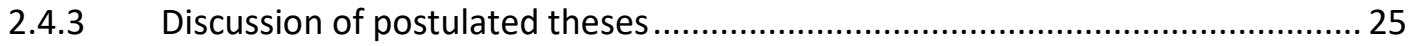

2.4.4 Application of selected feature cut-offs to test data .......................................... 26

2.4.5 Differentiation of serration within the crypt...................................................... 26

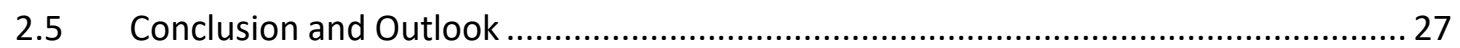

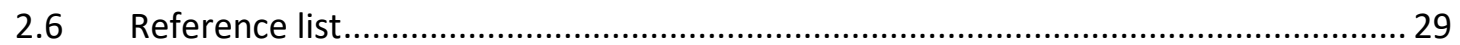

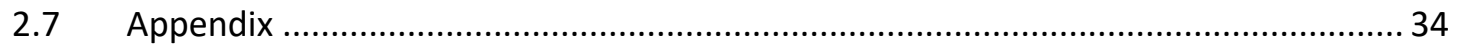

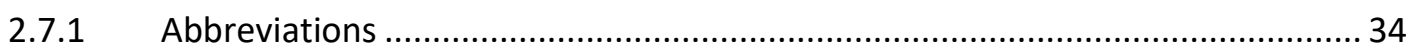

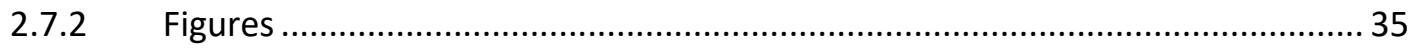

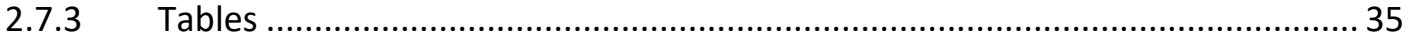

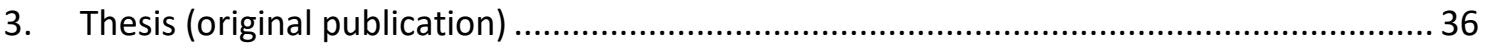

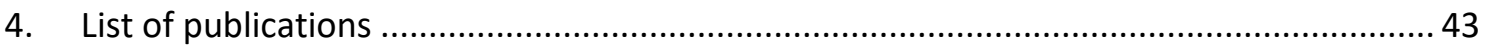




\section{Vorwort und Danksagung}

Bevor wir in die Thematik dieser Arbeit einsteigen, möchte ich Ihnen gerne über die Entstehung dieser Arbeit berichten, um die Gliederung der Dissertation verständlicher zu machen. Aufgrund meiner Vorbildung im Technik- und Informatikbereich war es für mich von besonderem Interesse, eine interdisziplinäre Arbeit zu verfassen, die sowohl medizinische als auch technische Inhalte vereinbart. Es ist zum einen spannend, verschiedene Wissensbereiche zu kombinieren und eine wissenschaftliche Arbeit daraus zu verfassen. Zum anderen habe ich während des Arbeitsprozesses oftmals festgestellt, dass es nicht einfach war, die Arbeit einzugruppieren. Die Arbeit hält sich an die formalen Rahmenbedingungen einer medizinischen Doktorarbeit. Leichte Abweichungen habe ich dennoch vorgenommen, um beiden Seiten, der medizinischen und der technischen Seite, gerecht zu werden. Da ich meine Studie in der Informatik publiziert habe, gehe ich in der Originalpublikation nur am Rande auf bestimmte Themen ein. Ich habe mich deswegen dazu entschlossen, die Originalpublikation zu erweitern und ein umfassenderes Exemplar der Dissertationspublikation zu verfassen. Ich habe dieses Kapitel „Thesis (Extended Publication)" genannt. In diesem Kapitel erscheint auch eine Einleitung, welche die Arbeit in ihren fachwissenschaftlichen Kontext einordnet. Da dies natürlich ein vor allem technischer Kontext ist, habe ich mich auf die wesentlichen Punkte beschränkt. 


\section{Abstract}

\section{Hintergrund und Ziele}

Diese Arbeit siedelt sich im Bereich der digitalen Pathologie an und befasst sich mit der Entwicklung und Evaluierung von Algorithmen zur zuverlässigen Computer-assistierten Diagnose von kolorektalen Läsionen auf histologischer Ebene. Mit der Einführung von digitalen Whole Slide Image Scannern gewinnt die digitale Pathologie eine immer größer werdende Bedeutung. Eine Computer-unterstützte Detektion und Klassifizierung neoplastischen Gewebes findet bereits in verschiedenen medizinischen Bereichen Anwendung, beispielsweise innerhalb der Gynäkologie (Zervix-Ca, Mamma-Ca) oder der Urologie (Prostata-Ca) [1]. Mit Hilfe Computer-assistierter Bildverarbeitung können Diagnosen objektiv und reproduzierbar gestellt werden. Dies ist insbesondere bei kolorektalen Läsionen ein Zugewinn, da hier die InterObserver-Varianz oft erheblich ist [2, 3]. Bezüglich der automatisierten Segmentierung von Kolondrüsen auf histologischer Ebene wurden bereits verschiedene Methoden mit vielversprechenden Ergebnissen getestet [4].

Ab dem 55. Lebensjahr wird in Deutschland als Früherkennung kolorektaler Karzinome (CRC) eine Koloskopie empfohlen, da hier die Inzidenz für CRC deutlich ansteigt [5]. Die Untersuchung wird dann je nach Befund in mehrjährigen Intervallen wiederholt. Bei etwa jedem vierten Patienten werden innerhalb der Koloskopie kolorektale Läsionen vorzeitig entdeckt und mittels Polypektomie therapiert, was die Mortalität von kolorektalen Karzinome erheblich senkt [6, 7, 8]. Die Polypen werden histologisch aufgearbeitet und ausgewertet. Um diesen arbeitsintensiven Prozess Computer-assistiert zu unterstützen, befasst sich diese Arbeit mit der Entwicklung von Algorithmen, welche Läsionen im Darmgewebe erkennen und diese den jeweiligen Entitäten zuordnen. Der Schwerpunkt dieser Arbeit liegt in der geeigneten Auswahl von Bildanalyse-Algorithmen, um eine robuste und zuverlässige Klassifikation zu erreichen. Zudem werden erste Ansätze für sowohl eine automatische, als auch semi-automatische Detektion von einzelnen Kolondrüsen im Rahmen der Doktorarbeit durchgeführt. Um eine geeignete Grundwahrheit für die Evaluation geeigneter Klassifikationsmerkmale zu finden, wird im weiteren Verlauf der semi-automatische Ansatz verfolgt.

\section{Material}

Es werden zwei voneinander unabhängige Datensätze in dieser Arbeit verwendet. Der erste Datensatz wird in zwei weitere Untergruppen unterteilt: einem Trainingsdatensatz und einem Testdatensatz. Dieser Datensatz wurde innerhalb einer Inter-Observer-Studie von zehn Experten, welche in der gastroenterologischen Pathologie spezialisiert sind, ausgewertet. Insgesamt besteht der Datensatz aus 200 digitalisierten Slides. Ein ausgewähltes Subset von 
37 Patientenfällen wird für die weitere Untersuchung der Bildanalyse-Algorithmen verwendet. Der zweite Datensatz von insgesamt 125 digitalisierten Slides wird von der Universität Bern gestellt, welcher von einem Experten der gastroenteropathologischen Pathologie, PD Dr. med. Tilman Rau, befundet wurde. Insgesamt werden 125 basale und 125 apikale Krypten aus 25 verschiedenen Patientenfällen in die Auswertung einbezogen.

\section{Methoden}

Es werden verschiedene Methoden und Algorithmen verwendet, um zum einen die Drüsenlumina adäquat zu detektieren und zum anderen diese in ihre entsprechenden Entitäten zu klassifizieren. Im ersten Teil werden diverse Schwellenwert- und Segmentationsalgorithmen getestet, im zweiten Teil werden verschiedene Merkmale extrahiert und evaluiert, um biologische Prozesse wie Serratierung und zytologische Dysplasie zu objektivieren. Diese Studie konzentriert sich vor allem auf Merkmale, die zum einen die Form adäquat wiedergeben, was vor allem hinsichtlich der Beschreibung des Prozesses der Serratierung sinnvoll ist. Zum anderen verwendet sie Merkmale, die sich auf die Farbintensität und Farbverteilung der einzelnen Drüse bezieht, um so eine objektive Beschreibung der zytologischen Dysplasie zu ermöglichen. Wir nehmen hier an, dass die Farbintensität und Farbverteilung die zytologische Dysplasie wiederspiegelt, da diese unter anderem durch Veränderungen der Kern-Zytoplasma-Relation mit Vergrößerung der Zellkerne sowie durch die (Pseudo-)Stratifizierung der Zellen und durch die Hyperchromasie der Zellkerne charakterisiert ist.

\section{Ergebnisse und Beobachtungen}

Die Ergebnisse zeigen, dass insbesondere im Fall der Serratierung vielversprechende Merkmale aufgezeigt werden konnten, um Krypten-Lumina in ihrer Serratierung computerunterstützt zu klassifizieren. Auch die zytoplasmatische Dysplasie konnte Histogramm-basiert ausgewertet werden. Eine computer-assistierte Methode zur Differenzierung von gesunden Darmgewebe, konventionellen Adenomen und serratierten Läsionen ist daher über einen Entscheidungsbaum möglich.

\section{Schlussfolgerungen}

Diese Arbeit zeigt, dass der in dieser Studie entwickelte Algorithmus zur computer-assistierten Diagnose hinsichtlich kolorektaler Läsionen robuste und präzise Ergebnisse liefert und eine Integration in einem größeren Kontext möglich ist. Zudem zeigt er auf, dass Prozesse innerhalb der Karzinogenese wie der Verlust von Serratierung oder eine Änderung der Serratierungsverteilung innerhalb der Kolondrüse präzise objektiviert werden kann. Dadurch ist es möglich, die in der Literatur beschriebenen Prozesse mit Hilfe dieses Algorithmus zu belegen und so die zugrundeliegenden Mechanismen besser zu verstehen. 


\section{Thesis (extended publication)}

The second chapter of this work is an extended version of the original publication, which is presented in chapter 3. Because of the publication guidelines and because of the technical context of the journal, not all applied methods could be mentioned in the original publication and detailed descriptions are missing. Therefore, this chapter is added to show the work in detail.

\subsection{Introduction}

In this chapter, we start with the motivation of this study, why computer-assisted diagnosis is useful in the context of precursor colorectal lesions in histopathology. Then, a short review of digital pathology from past to present with focus on computer-assisted image analysis is given. Applications already used in histopathology are demonstrated. In the last part, three theses are postulated which will be investigated, evaluated and discussed in this work.

\subsubsection{Precursor colorectal lesions: Is computer-assisted diagnosis useful?}

Computer-assisted diagnosis within the clinical workflow is reasonable, because it enables time saving, reproducibility and a better understanding of underlying mechanisms. A high number of histopathological data is obtained within colonoscopy screening programs (see also next paragraph Epidemiology of $(R C)$. Many slides have to be classified and diagnosed by a pathologist. Thus, computer-assisted diagnosis can be used as a beneficial adjunct in the clinical workflow enabling time saving. Furthermore, it provides high reproducibility and consistency, which is of particular gain in terms of colorectal lesions, since inter-observer-variance is often significant $[2,3]$.

Epidemiology of colorectal cancer (CRC): $\mathrm{CRC}$ is the fourth most common cancer in men worldwide and colonoscopy screening programs are a crucial strategy for CRC prevention. A polypectomy is performed in about every fourth patient [7, 8]. In Germany, the incidence of CRC is approximately 60.000 per year. CRC is the third most common cancer of men after prostate and lung cancer, and the second most common cancer of women after breast cancer (see also Figure 1). In terms of mortality, CRC is the third most common cancer death of men after prostate cancer, and the third most common one of women after breast and lung cancer. Ninety percent of CRCs are diagnosed after the age of fifty. Due to secondary prevention programs such as colonoscopy screening programs, incidence and mortality rates have been declined [6]. In addition to secondary prevention, many studies concerning primary prevention have been conducted (a short overview is given in the next paragraph Risk factors for CRC). Epidemiological 
data referred to the German population is based on the "Zentrum für Krebsregisterdaten des Robert-Koch-Instituts" from the year 2012 (www.krebsdaten.de).

Figure 1: Relative cancer frequency

Percentage of most common cancers of all cancer cases for men and women in Germany

(compiled after "Zentrum für Krebsregisterdaten des Robert-Koch-Instituts", 2012; www.krebsregister.de)
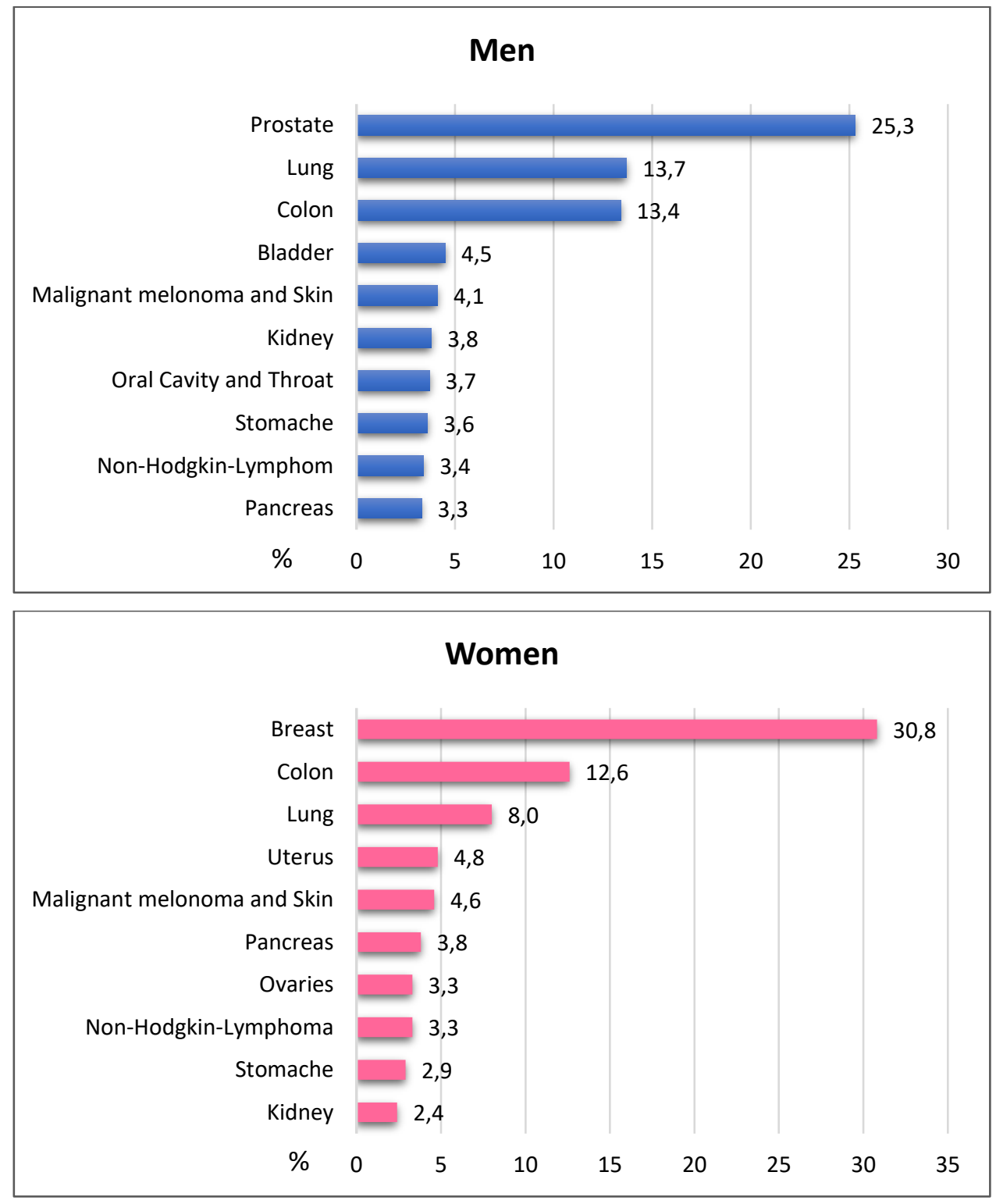

Risk factors for CRC: There are diverse risk factors for CRC. Predisposing risk factors are connected to e. g. i) genetics such as family history, ii) lifestyle such as alcohol, smoking, obesity and diet and iii) diseases with elevated risk for CRC such as inflammatory bowel diseases (Crohn's disease, ulcerative colitis). Accordingly, protective factors are e. g. physical activity or low meat diet. Other protective factors are the use of oral contraceptives, multivitamins or 
estrogen replacement (see also Table 1). Modifiable factors are written in italic text seen in Table 1 and account for primary prevention of CRC [9].

Table 1: Risk Factors for Colorectal Cancer

From American Cancer Society. Cancer Facts and Figures 2002. Atlanta: American Cancer Society; 2002:20. (Data from Colditz et al., 2000 [10])

\begin{tabular}{ll}
\hline Factor & Relative Risk \\
\hline Family history (first-degree relative) & 1.8 \\
Physical Inactivity (<3hrs/week) & 1.7 \\
Inflammatory bowel disease & 1.5 \\
Obesity & 1.5 \\
Red Meat & 1.5 \\
Smoking & 1.5 \\
Alcohol (>1drink/day) & 1.4 \\
High vegetable consumption ( $\geq 5$ servings/day) & 0.7 \\
Oral contraceptive use ( $\geq 5$ yrs) & 0.7 \\
Estrogen replacement ( $\geq 5$ yrs) & 0.8 \\
Multivitamins containing folic acid & 0.5 \\
\hline
\end{tabular}

Another aspect why computer-assisted diagnosis is reasonable concerning colorectal lesions are alterations in morphometry, color and color distribution manifesting in colon crypts during carcinogenesis. Those characteristics can be evaluated with the help of image analysis and brought into the context of computer-assisted diagnosis. CRC arises from two main pathways: the conventional adenoma pathway [11] and the serrated pathway [12, 13, 14]. The conventional adenoma pathway is the more common one accounting for approximately 70 to $80 \%$ of all CRCs, whereas the serrated pathway accounts for about 20 to $30 \%$. The duration of the development from conventional adenoma to cancer is approximately 15 years. The duration of carcinogenesis in terms of the serrated pathway is dependent of foci of true dysplasia within the polyps [9]. In the conventional adenoma pathway, the process of cytological dysplasia plays a key role; in the serrated pathway, the process of serration is essential. The aim of this study is to investigate and evaluate methods of image analysis for describing cytological dysplasia and serration, so that a first cornerstone towards computer-assisted diagnosis for colorectal lesions can be set.

\subsubsection{Digital Pathology: Past to Present}

In this chapter, we present an introduction of digital pathology (DP). DP is nowadays a wide and diverse field. In its simplest form, digital pathology or imaging is the conversion of an optical image of a conventional pathologic slide into a digital image e.g. by a camera or scanner and can be depicted on a digital screen [15]. Nowadays, DP reaches further. We can not only investigate 
the digitized image on a screen, we can archive the data, we can transmit data electronically across distances via web-based software, discuss results, mark important structures, etc. The topic of this study will focus on a field that has been rapidly rising during the last years: the computer-aided analysis of pathological images, or in short terms "image analysis". The next paragraphs will give a short introduction of the beginning of DP and its fields of application, before we will get to the topic of image analysis.

The digitalization of microscopic slides had its beginning already in the late 1960s. Here, the term telepathology was coined and first applications in the clinical workflow were introduced [16]. Weinstein et al. defined the term telepathology as "the practice of pathology over a long distance" [17]. In addition, Table 2 shows the most important milestones in the development of DP. There were two competing telepathology technologies which both had their beginnings in the mid-1980s: the static image (store-and-forward) telepathology and the dynamic (real time) robotic telepathology. The former technology is performed with an on-site pathologist, who selects regions of interest in the histopathological slide and then transfers this image to an offsite telepathologist for remote evaluation. The latter one (dynamic robotic telepathology) does not have an on-site pathologist. An off-site telepathologist can use remote robotic control of all light microscopic functions such as magnification, focus, illumination and field selection. A hybrid system, combining both, the static and the dynamic system, was developed in Norway in 1989. This system was the precursor of the dual image dynamic robotic/static image telepathology used nowadays. Requirements for the hybrid system were particularly the availability of broad band Internet and the high resolution of transferred images. The dual image dynamic robotic/static image telepathology had its breakthrough in 2011. The progress of this technology was mainly supported by the introduction of whole slide imaging (WSI). "WSI allows the digital capture of the entire tissue sample at high resolution and the viewing of the slide at any position and at any magnification" [18]. This advance was mainly supported by good stitching algorithms and high image storage capacity. Digitized WSI slides could be stored on a server and then viewed by an off-site pathologist. Figure 2 shows the concept of this dual image technology also referred to as WSI-enhanced dynamic-robotic telepathology. Advantages of WSI and dynamic-robotic telepathology are combined. On the top of Figure 2, the whole histopathological landscape is depicted. In this landscape it is possible to select a region of interest in which the functions of robotic-dynamic features such as up-and down focusing etc. can be applied in real-time. In Figure 2 (bottom), the region of interest in marked with a black rectangle [17]. 
Figure 2: Concept of WSI-enhanced dynamic-robotic telepathology

Top: WSI, histopathological landscape; Bottom: region of interest within the WSI marked with a black rectangle. Navigation in the $x_{-}^{-}, y^{-}$, and $z$-axes in real-time using dynamic-robotic telepathology is possible within the region of interest (compiled after Weinstein et al 2012, modified)

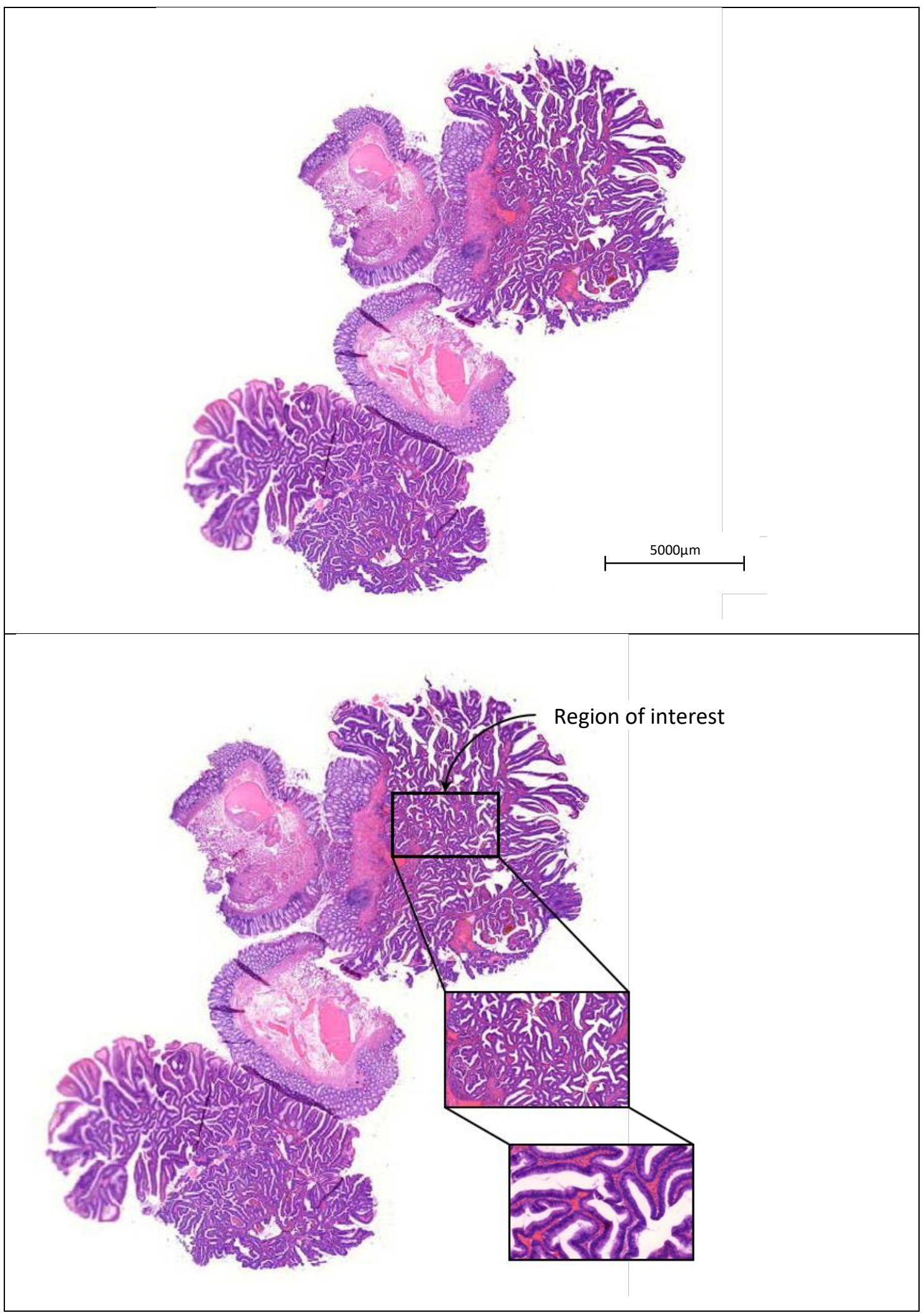


Table 2: DP: past to present

Overview of milestones within the classes of telepathology systems (compiled after Weinstein et al. 2012, modified)

\begin{tabular}{lc}
\hline Class of telepathology system & Year \\
\hline $\begin{array}{l}\text { Real-time imaging telepathology } \\
\text { Clinical applications }\end{array}$ & 1968 \\
Dynamic-robotic telepathology & 1986 \\
\hline Static-image telepathology & 1989 \\
Static-robotic image telepathology & 1991 \\
Whole Slide Imaging & \\
\hline Multi-Modality digital image telepathology & 1989 \\
Hybrid dynamic robotic/static imaging & 2011 \\
Dual image dynamic robotic/static image & \\
\hline
\end{tabular}

\subsubsection{Digital Pathology: Image Analysis and its application}

DP can be employed in different fields such as telepathology, remote consultation, tumor boards, biobanking, education and primary diagnosis using image analysis [15, 19]. Since computational image analysis is the topic of this study, we will describe this issue in more detail.

With the help of image analysis, it is possible to "measure pathology". Quantitative data can be retrieved and assessed from a digitized image. It allows simple measurements such as intensity, length or cell count as well as more complex ones such as tissue structure. In the decision-making process which normally is based on subjective visual interpretation, the computer can be used as an objective aid [20]. Thus, providing high consistency and reproducibility, as well as low variation that exists in image interpretation.

Key words and main operations that are connected to image analysis in terms of DP are annotation, segmentation, feature extraction, tissue classification and quantitative immunohistochemistry $[1,19]$. These processes are explained in the following. Processes that are employed in this study are described in more detail and an example from this current study is added.

Annotation: A selection of an image is not indispensable but has advantages in the ongoing workflow. By selecting a region of interest, information that is not needed for further computation can be omitted. This enables a focus-orientated analysis and saves computation time. In image analysis, this process of selection is often referred to as annotation. There are 
different ways to select this region of interest. Parameters like size, shape and the mode how this selection is done (manually or automatically) are variable. In this work, a rectangular annotation is retrieved manually. As seen in Figure 3, only a subset of the digitized whole slide image is annotated and used for further investigation.

Figure 3: Whole Slide Image of hyperplastic polyp

The annotation of the region of interest is marked with a rectangular. (Picture taken by the software Pannoramic Viewer Version 1.15.3, 3DHISTECH Ltd, Budapest, Hungary)

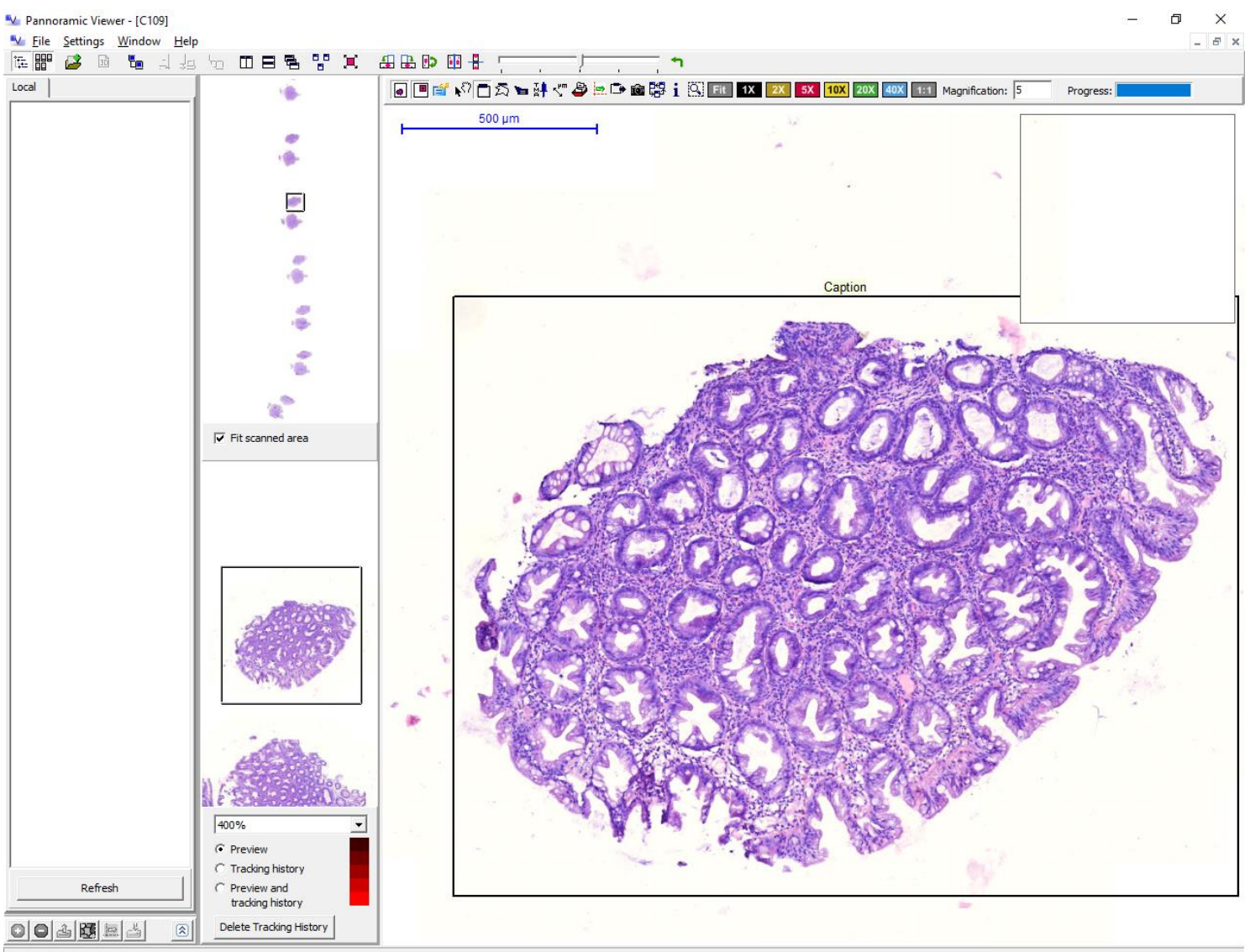

Segmentation: After having selected a region of interest, entities of interest need to be identified. In the context of histopathology, entities are for example nuclei, glands or tumor regions. Like in the process of annotation, segmentation can be conducted with different methods. Again, there are manual as well as automatic methods. Well-established automatic methods in image analysis that have been already applied in the context of DP are for example active contour, graph-based, stochastic or deep learning models [21, 22, 23, 24]. These methods can be used in diverse contexts. A very common topic is the segmentation of cell nuclei [21,24]. There are many software systems such as the free open software CellProfiler or QuPath or the commercial software by Definiens ${ }^{\circledR}$ or by IndicaLabs ${ }^{\circledR}$ in which these segmentation algorithms are already applied $[25,26]$. 
In this study, we segment the crypt lumen and the crypt itself. In Figure 4, segmentation results are depicted and colored in black. Within this study, different approaches for automatic (also referred to as unsupervised) segmentations were employed such as the Otsu threshold approach or the spectral angle mapper approach. There are diverse work groups that have been and are still investigating automatic segmentation of glandular structures of colon tissue [23]. We compared the segmentation results of crypt lumen conducted by the automatic and by the semi-automatic approach. It showed that the semi-automatic approach is still more precise in single cases than the automatic one. Since segmentation results are used as ground truth in this study, we continued to use the semi-automatic segmentation for the crypt lumen and a manual segmentation for the crypt itself. The semi-automatic segmentation is based on an activecontour model. It is a region-growing approach based on color and structure similarity with manual seed points [26]. For reasons of clarity and because this approach was not followed in the long term, a detailed description of employed automated segmentation algorithm and its results are not included in this work.

Figure 4: Segmentation of crypt lumen and crypt itself Left Segmentation of 10 crypt lumina Right Segmentation of 10 crypts. Segmentation results are colored in black.
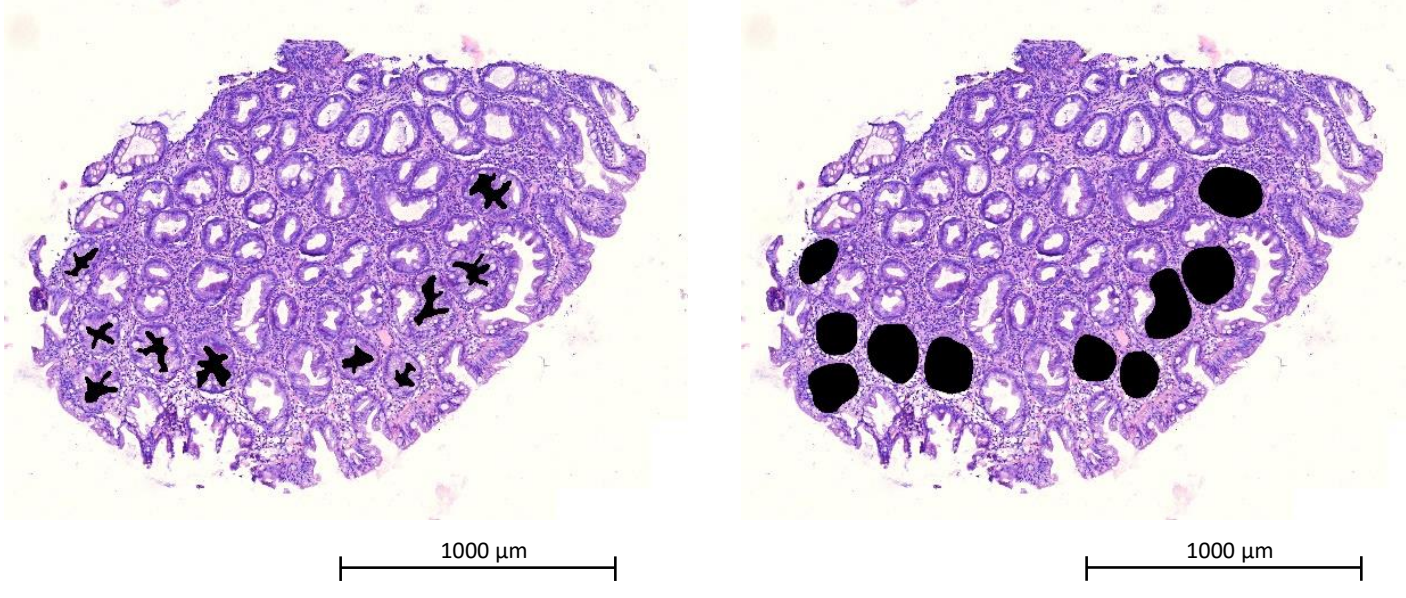

Feature Extraction: Once objects of interest are segmented, they can be measured quantitively with the so-called feature extraction. A feature is an individual measurable quality or characteristic of an object being observed. Simple measurements such as size or area of the segmented object can be performed, but also more complex ones such as homogeneity or entropy. With the help of computational measurements, characteristics that are not visually discernable can be shown in the form of values or colors. Thus, a robust and objective evaluation is possible. 
In this study, the object of interest is on the one hand the crypt lumen, and on the other hand the crypt itself. Morphometric characteristics are computed for each segmented crypt lumen using shape factors such as circularity or solidity. Values obtained by these computations are used to describe the degree of serration. By quantifying the process of serration, subjectivity and variability can be removed in pathology diagnosis. During the work process, common databases did not show studies investigating serration of colorectal lesions with the help of image analysis. Nevertheless, literature in the field of informatics, or more specifically in the field of image processing, demonstrates various ways for describing irregularities of objects with the help of shape factors [26]. Therefore, we employ and evaluate these well-established shape factors in the context of histopathological data, in specific, on colorectal lesions in this study.

Next to the quantitative measurement of crypt lumen, the process of cytological dysplasia is described with the help of image analysis in this study. Since nuclear alterations play a key role in carcinogenesis, this process is a well-investigated field in terms of computer-aided approaches. In the previous paragraph Segmentation, diverse approaches that help identifying nuclei automatically are already mentioned. But not only in the field of segmentation, but also in the field of Feature Extraction many studies have been conducted supporting quantitative evaluation of nuclei [1]. These studies have focused on three main features in terms of nuclei alterations. First, morphometric features such as nuclear size and shape; second, densitometric features such as nuclear density and chromatin disorganization; third, cell counts such as mitotic indices. The latter one, mitotic cell counts, helps e. g. to grade tumor types. For example, in 1985 Baak et al. [27] introduced a simple mitotic activity index and uses, next to other parameters such as tumor size and lymph node status, the mitotic cell counts for prognosis of breast cancer. With the help of image analysis, exact numbers of mitotic cell counts can be retrieved and used. In gastroenterology, the feature optical density of stained nuclei is measured to discover dysplasia in Barrett oesophagus [28]. In urology, prostate neoplasia is detected more easily by visualizing chromatin disorder [1]. In this study, we use a combination of densitometric and cellular organization features to objectively describe and classify cytological dysplasia in colorectal lesions. To provide this combination, histogram-based features are applied.

Tissue architecture/classification: Measuring tissue architecture is a complex procedure. Diseases such as cancer tend to manifest in tissue alterations. Thus, an automated and objective tissue classification would be useful in the clinical workflow. There are different approaches of how to measure diverse tissue patterns. In the previously mentioned paragraph we explained the process of feature extraction. This approach can be used for architectural changes as well $[29,30]$. There are diverse examples, where feature extraction is applied in a medical context. 
In hematology, for example, this technique was employed developing software systems for automated analysis of blood and bone marrow slides [31, 32]. But not only within cellular analysis, but also within H\&E stained examples this approach can be used (see next paragraph). Madabushi et al. (2017) mention two different categories for tissue classification: handcrafted and unsupervised feature-based approaches. The former one can be connected to specific measurable attributes, the latter one is less intuitive, but broadly applicable and is often based on deep learning strategies.

One example for automated tissue architecture with a handcrafted feature-based approach is disease grading in terms of prostate cancer. By using wavelet and tissue texture features, Jafari-Khouzaniv and Soltanian-Zadeh (2003) are able to establish an automated Gleason grading algorithm [33]. Thus, images can be attributed with a low or a high Gleason grade automatically. When handcrafted features are employed, certain features are selected to describe tissue architecture in a feasible way. For example, another feature to classify the disease grade of prostate cancer, is the entropy of gland directions [34]. More transparency is provided with regard to the handcrafted feature-based approach. The unsupervised feature-based approach is often based on deep learning strategies that have been of particular interest in the last years. As written above, this method is less intuitive, and less transparency is provided. Deep learning strategies have their strength in describing very complex patterns and can be applied to different tasks without the need to define handcrafted features. Ertosun and Rubin (2015), for example, employed this approach for automated grading of gliomas in digital pathology images [35].

Quantitative Immunhistochemistry: The last important application of image analysis in DP we want to mention in this chapter is quantitative immunhistochemistry. Immunhistochemical stainings are widely used in the diagnosis of abnormal cells which occur in neoplastic tissue and complements classical histological examinations. Molecular tissue biomarkers are mainly used to predict a malignant tumor's response to a specific drug enabling personalized medicine [15]. Examples of tissues in which biomarkers are used are amongst others breast cancer, lung cancer, lymphoma, prostate cancer and melanoma $[36,37,38,18]$. With the help of image analysis, markers can be quantified (semi-)automatically. A well-known example is the oestrogen receptor (nuclear marker) or the human epidermal growth factor receptor 2 HER2/neu (cell membrane marker) [39] that are used for diagnosis and therapy in breast cancer. It is seen that even though the visual interpretations are conducted by experienced pathologists, there are still considerable differences between observers. By image analysis, higher reproducibility rates are provided $[41,42,43]$. 


\subsubsection{Aim of this study: Image Analysis of precursor colorectal lesions}

With continuously rising numbers of participants in colorectal screening programs as well as removed polyps, an increased demand exists for DP in terms of an automated pre-screening and classification of colorectal lesions in digitized histological slides. Image analysis that is based on nuclear morphometry and tissue architecture is a challenging, but promising field in DP. Diverse approaches were conducted on different tissues such as prostate or cervix [1]. In this study, we propose an initial interactive image analysis for precursor colorectal lesions by describing and distinguishing two significant processes occurring in such lesions: serration and cytological dysplasia. Describing serration is one important cue, since serration is related to the two broad pathways of colorectal carcinogenesis: the adenoma-carcinoma sequence (also known as Vogelstein model [11]) and the more recently described serrated pathway [12, 13, 14]. In this study, we examine if shape descriptors such as circularity, solidity, etc. are suitable for assessing the saw-toothed pattern of the white field area of the crypt also referred to as crypt lumen. A second important cue for classifying lesions is cytological dysplasia. In 2010, the WHO classified serrated colonic polyps into non-dysplastic and dysplastic [42]. Furthermore, non-serrated lesions such as classic adenomas can be distinguished from healthy tissue (normal mucosa) when cytological dysplasia is taken into account. Cytological dysplasia is very complex. It expresses changes in architecture, shape and color. We assume that changes, e.g. in nucleuscytoplasm ratio, (pseudo-) stratification, hyperchromaticity (which are all features of cytological dysplasia) are connected to changes in color and color distribution within the affected area. Therefore, we investigate if histogram-based features are applicable to describe cytological dysplastic processes. In summary, we postulate and examine three theses

1. A tree classifier is able to distinguish between healthy tissue, classic adenomas, and serrated lesions.

2. Serration of crypt lumen can be described precisely by adequate geometrical features.

3. Cytological dysplasia of crypt can be characterized and differentiated by histogrambased features.

In Figure 5, the decision tree visualizes the workflow and the underlying idea of this study: First, separating lesions into non-serrated and serrated, second, dividing lesions into nondysplastic and dysplastic. In order to distinguish premalignant lesions from healthy tissue, normal mucosa (NM) is added in the diagram on the left side. In the class NM, neither serration nor cytological dysplasia is pronounced. 
Figure 5: Decision Tree of colorectal premalignant lesions

Decision Tree of colorectal premalignant lesions based on the WHO classification, 2010. On the left side, the class $N M$ is added. $N M=$ normal mucosa, $C A D=$ classic adenoma, $\mathrm{HP}=$ hyperplastic polyp, SSA=sessile serrated adenoma without dysplasia, SSAD=SSA with dysplasia, TSA=traditional serrated adenoma.

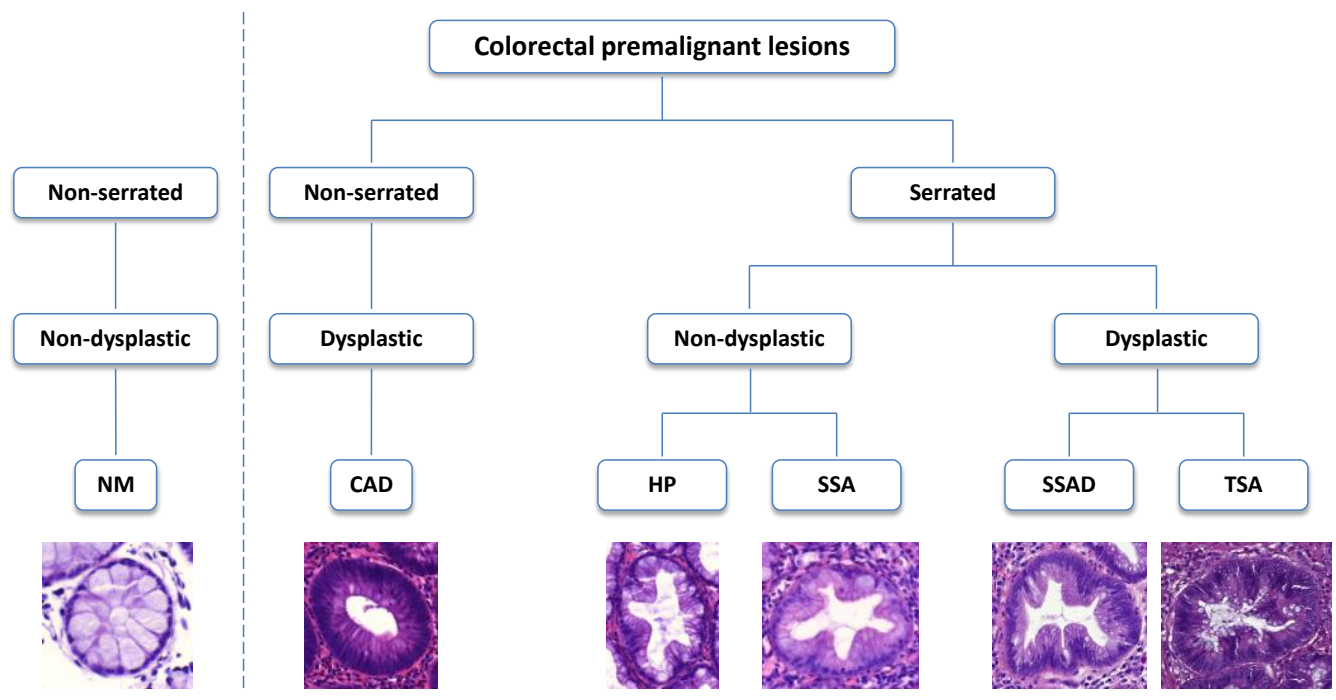

\subsection{Material}

In this chapter, data sets used in this study are introduced. First, we use a training data set as reference data to find and evaluate robust and adequate features describing serration and cytological dysplasia. These features and cut-offs are then applied to a second test data set. As a third data set, a data set is used that subdivides crypts into the crypt at the surface and the respective crypt at the base, since we do not only want to look at a crypt in two dimensions, but also in its third dimension. Thus, additionally the degree of serration in the upper half of the crypt compared to the lower part is investigated.

\subsubsection{Training data set}

The training data set is obtained from a previously conducted inter-observer study [3]. Ten experts, specialized in GI pathology, from all over Europe classified precursor lesions in three different rounds. The study set consists of 200 lesions including the following classes of colorectal lesions: normal mucosa (NM), hyperplastic polyp (HP), sessile serrated adenoma without dysplasia (SSA), traditional serrated adenoma (TSA), classical adenoma (CAD) and mixed-type polyp (MIT). The tissue is stained with H\&E staining and the microscopic slides are digitalized with a Zeiss Mirax scanner with a maximal resolution of 400x amplification, which corresponds to $0.23 \mu \mathrm{m}$ per pixel. In order to achieve representative and robust features of crypt lumina and crypt itself, unambiguous data is important. Therefore, lesions are chosen in which 
all 10 experts agree on the same diagnosis and are used as ground truth. Classes with sufficient data that are chosen for further investigation are NM, HP, SSA and CAD.

In Table 3 the total number of slides according to their class is shown. It shows the number of slides all pathologists classify with the same diagnosis (10 consistent classification results) as well as the number of slides the classification differs (less than 10 consistent classification results). Each pathologist classified 200 slides, so that in total 2000 classification results were obtained. The classification results for the classes NM, HP, SSA and CAD are summed up and depicted in Figure 6. Here, it is seen, that the highest diversity/inconsistency of classification results are found in the classes HP and SSA. As ground truth, the mode of the ten classification results on the respective slide was chosen.

For the training data set, two hundred crypts from 20 different cases are selected from slides with consistent classification results (see also Table 4). Crypt lumen and crypt itself are segmented using a semi-automatic approach. For lumen segmentation, a region-growing approach based on color and structure similarity is applied with manual seed points [26]; the crypt itself is segmented manually.

Table 3: Descriptive statistic of Data Set I

a) Number of slides for the classes NM, HP, SSA, TSA, CAD and MIT, divided into the number of slides with consistent classification results from all ten experts and into the number of slides with inconsistent classification results. b) Diagram visualization of a) for the classes NM HP, SSA, TSA and CAD.

a)

\begin{tabular}{lccc}
\hline Class & $\begin{array}{l}\text { \# Slides } \\
\text { consistent } \\
\text { classific. }\end{array}$ & $\begin{array}{l}\text { \# Slides } \\
\text { inconsistent } \\
\text { classific. }\end{array}$ & $\begin{array}{l}\text { \# Slides } \\
\text { Total }\end{array}$ \\
\hline NM & 7 & 4 & 11 \\
HP & 11 & 61 & 72 \\
SSA & 12 & 39 & 51 \\
TSA & 1 & 8 & 9 \\
CAD & 29 & 22 & 51 \\
MIT & - & 6 & 6 \\
\hline Total & 60 & 140 & 200 \\
\hline
\end{tabular}

b)

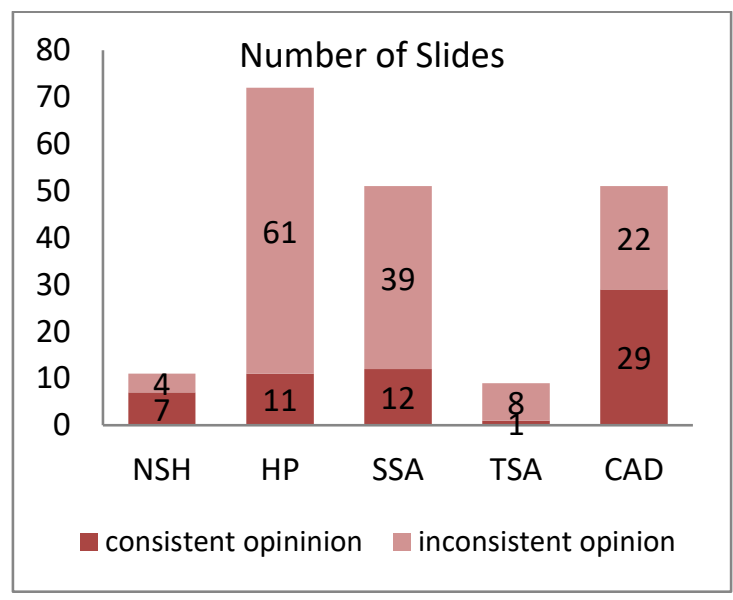


Figure 6: Descriptive statistic of classification results for Data Set I

Classification rate in percentage for the classes NM, HP, SSA and CAD.

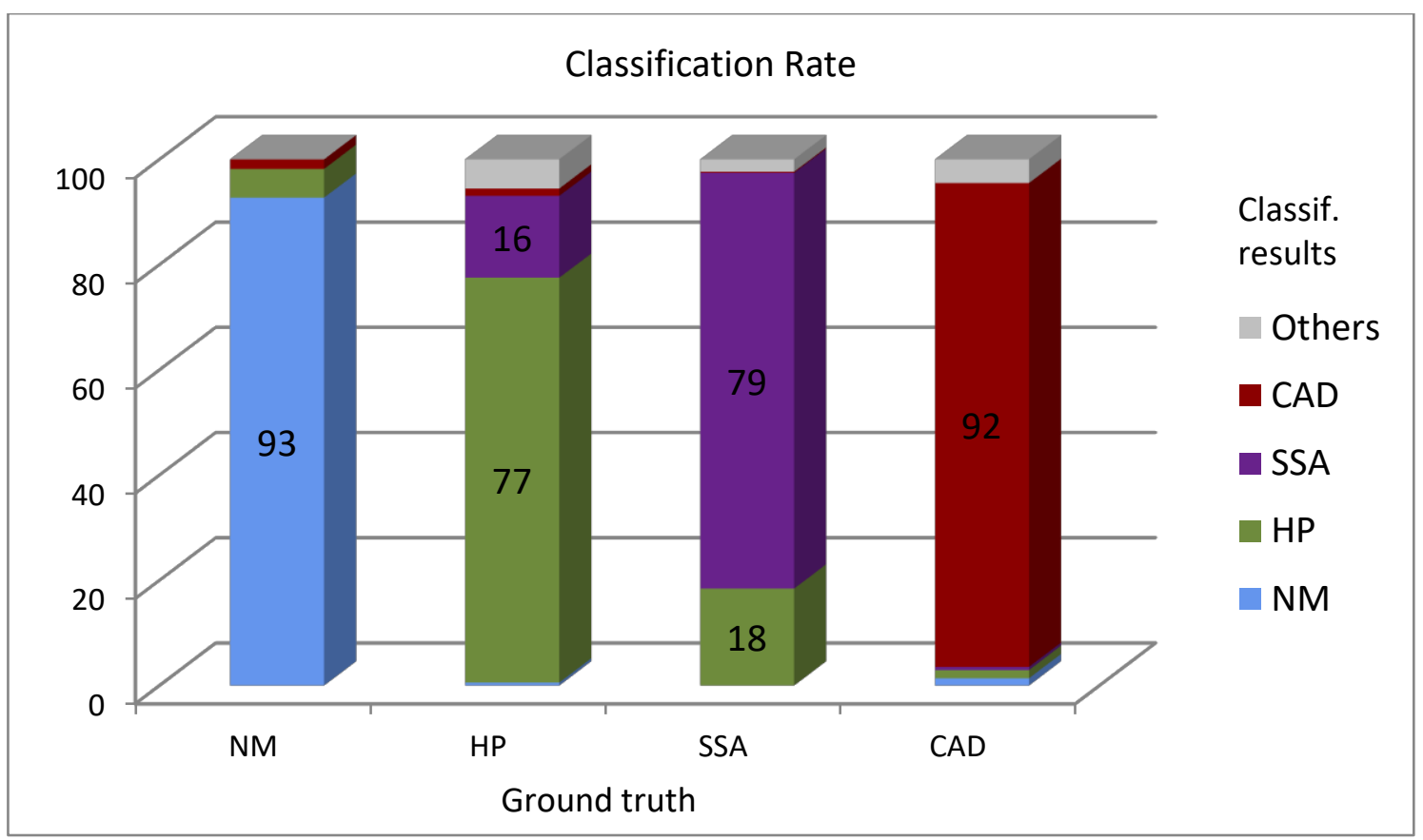

\subsubsection{Test data set}

The test data set is obtained in a similar way like the training data set (see previous chapter). The only difference appears for the class NM, since only two slides all experts agreed on are left for annotation. This makes a total number of 20 crypts instead of 50 in this class. Therefore, in total 17 different cases instead of 20 are selected from slides with consistent classification results.

\subsubsection{Data set III}

Another data set (referred to as Data Set III) is provided from the Institute of Pathology, University of Bern, Switzerland, including cases of five different classes (CAD, HP, SSA, SSAD, TSA). Like the training and test data set, the tissue is stained with H\&E staining and the microscopic slides are digitalized with a Zeiss Mirax scanner with a maximal resolution of 400x amplification corresponding to $0.23 \mu \mathrm{m}$ per pixel. In total, about 100 slides are classified by an expert in gastroenteropathology. In this collection, 25 basal crypts and its respective apical crypts from five different samples are marked by an expert in GI pathology for each class (basal referring to the lower half, apical to the upper half of the crypt; see also Table 4). When the tissue is annotated, the entity of the sample is masked (not known to the subject). This data set is used for investigation of the distribution of serration degree within the crypt. 
Table 4: Number of crypts and crypt lumina annotated in the three chosen data sets Data sets: Training data set, Test data set, Data Set III

\begin{tabular}{lccccccc}
\hline & \# NM & \# CAD & \# HP & \# SSA & \# SSAD & \# TSA & \# Total \\
\hline Training Data & 50 & 50 & 50 & 50 & - & - & 200 \\
Test Data & 20 & 50 & 50 & 50 & - & - & 180 \\
& & & & & & & \\
Data Set III & & & & & & & \\
- basal crypts & - & 25 & 25 & 25 & 25 & 25 & 125 \\
- apical crypts & - & 25 & 25 & 25 & 25 & 25 & 125 \\
\hline
\end{tabular}

\subsection{Methods}

In this chapter, we give a short introduction of the chosen image-processing methods we use for describing serration (see Chapter 4.1. Shape descriptors) and cytological dysplasia (see Chapter 4.2. Histogram-based features). In each subchapter, we have a closer look on a special feature which will be relevant during the further procedure in this study.

\subsubsection{Description of serration with geometric features}

In order to prove the first thesis ("serration"), the training data set is used to find appropriate shape descriptors that distinguish precisely non-serrated from serrated crypt lumina. Based on the above mentioned interactive image annotation, a quantitative feature-based analysis is conducted. As representative classes, we use NM and CAD for non-serrated crypts and HP and SSA for serrated crypts. On this data set, nine well-established shape descriptors are evaluated including area, perimeter, area ratio $\left(\frac{\text { Lumen Area }}{\text { Crypt Area }}\right)$, major and minor axis of fitted ellipse, aspect ratio $\left(\frac{\text { Major axis }}{\text { Minor axis }}\right)$, circularity $\left(4 \pi \frac{\text { Area }}{\text { Perimeter }^{2}}\right)$, roundness $\left(\frac{4 * \text { Area }}{\pi * \text { Major axis }^{2}}\right)$ and solidity $\left(\frac{\text { Area }}{\text { Convex hull area }}\right)$. In Table 5, the last-mentioned shape descriptors are specified in more detail regarding its representation and range.

Table 5: Description of selected shape descriptors

\begin{tabular}{|c|c|c|c|}
\hline Parameter & Equation & Representation for & Range \\
\hline Aspect ratio & $\frac{\text { Major axis of fitted ellipse }}{\text { Minor axis of fitted ellipse }}$ & Elongation & $\{1 ; \infty\}$ whereas circle $=1$ \\
\hline Roundness & $\frac{4 * \text { Area }}{\pi * \text { Major axis }}$ & Elongation & $\{0 ; 1\}$ whereas circle $=1$ \\
\hline Circularity & $4 \pi \frac{\text { Area }}{\text { Perimeter }^{2}}$ & Irregularity & $\{0 ; 1\}$ whereas circle $=1$ \\
\hline Solidity & $\frac{\text { Area }}{\text { Convex hull area }}$ & Irregularity & $\{0 ; 1\}$ whereas circle $=1$ \\
\hline
\end{tabular}




\section{The feature solidity in more detail}

An illustration of the shape descriptor solidity is given in Table 6 . The lumen area is related to its convex hull area. Low solidity values stand for a low congruence of lumen area and its convex hull area, whereas values close to 1 show a high congruence.

Table 6: Illustration of the feature solidity applied to an exemplary crypt lumen

Original crypt $\quad \begin{gathered}\text { Convex Hull Area } \\ \text { (blue outline) }\end{gathered}$ Area $\frac{\text { Equation of solidity }}{\text { Convex Area }}=0.64$

Furthermore, a small example is shown in Table 7, comparing shape descriptors of a non-serrated crypt lumen (NM) to a serrated crypt lumen (SSA). As seen in Table 5, a circle reaches the value 1 for the shape descriptors aspect ratio, roundness, circularity and solidity. The first two descriptors represent elongation. In this example it is seen, that the non-serrated gland reaches values close to 1 (aspect ratio $=1.08$, roundness $=0.93$ ) meaning it is marginally elongated, whereas the serrated gland deviates from the value 1 (aspect ratio $=1.81$, roundness $=0.55)$. Of particular interest are also the last two descriptors circularity and solidity, since they represent irregularity, a characteristic highly present in serrated lesions. The non-serrated crypt shows values close to 1 (circularity $=0.91$, solidity $=0.95$ ), whereas the serrated crypt reaches lower values (circularity $=0.35$, solidity $=0.64$ )

Table 7: Results of shape descriptors for a non-serrated crypt compared to a serrated crypt

\begin{tabular}{lcc}
\hline & Non-serrated crypt (NM) & 9.36 \\
& 0.06 & 18.40 \\
Area & 0.88 & 4.64 \\
Perimeter & 0.28 & 2.57 \\
Minor axis & 0.26 & 1.81 \\
Aspect ratio & 1.08 & 0.55 \\
Roundness & 0.93 & 0.35 \\
Circularity & 0.91 & $\mathbf{0 . 6 4}$ \\
Solidity & 0.95 & \\
\hline
\end{tabular}




\subsubsection{Description of cytological dysplasia with histogram-based features}

To prove the second thesis ("cytological dysplasia"), the training data set is used to evaluate if histogram-based features are an adequate approach to describe dysplasia distinguishing non-dysplastic from dysplastic crypts. As representative class, we use the class NM for non-dysplastic crypts and the class CAD for dysplastic crypts. This differentiation is approached with histogram-based features such as mean, mode, min, max, variance, skewness and kurtosis (see also Table 8) which were obtained on different color channels such as Gray, Red, Green, Blue, Hue, Saturation and Brightness (see also Table 9).

Table 8: Description of selected histogram-based features

\begin{tabular}{lll}
\hline Parameter & Equation & Range \\
Mean & $\bar{x}=\frac{1}{n} \sum_{i=1}^{n} x_{i}$ & \\
Variance & $\sigma=\frac{1}{n-1} \sum_{i=1}^{n}\left(x_{i}-\bar{x}\right)^{2}$ & \\
Skewness & $v=\frac{1}{n} \sum_{i=1}^{n}\left(\frac{x_{i}-\bar{x}}{s}\right)^{3}$ & $<0$ (negative skew): left-tailed \\
Kurtosis & $w=\frac{1}{n} \sum_{i=1}^{n}\left(\frac{x_{i}-\bar{x}}{s}\right)^{4}$ & $<0$ p platykurtosis \\
& & $>0:$ leptokurtosis
\end{tabular}

Table 9: Color spaces and its channels

\begin{tabular}{ll}
\hline Color space & Channels \\
\hline 8-bit & Gray \\
RGB Color & Red, Green, Blue \\
HSB & Hue, Saturation, Brightness \\
CIELAB & Luminance \\
\hline
\end{tabular}

\section{The feature skewness in more detail}

The histogram-based feature skewness is now presented in more detail. Cytological dysplasia often impresses with hyperchromatic and stratified cell nuclei. The nuclei are more pronounced than cytoplasma, and the crypt itself appears darker. Thus, a right-tailed distribution of the histogram is presumed for dysplastic crypts with skewness values greater than 0 . When there is no cytological dysplasia like in normal mucosa, the cytoplasma is more pronounced than nuclei, and the crypt itself appears lighter. A right-tailed distribution of the histogram is presumed. Thus, the feature skewness has values less than 0 . 
In Table 10 this issue is explained in different ways. The 8-bit image (see also Table 10a) shows a lighter appearance of crypts according to non-dysplastic normal mucosa and a darker appearance according to dysplastic classical adenoma. The histograms of these images are given in Table 10b. For NM, it shows a left-tailed distribution, since there are more pixels with lighter/higher values and a right-tailed distribution is seen for the CAD-image, where there are more pixels with darker/lower values. Table 10c shows the histogram-based features in numbers (NM: skewness $=-0.91$, CAD: skewness $=1.26)$. In this example, the presumption fits. But we also have to take into account, that staining, illumination, etc. have an influence on histogram-based features. Therefore, an image pre-processing eliminating these biases is inevitable when brought to a greater context.

Table 10: Illustration of the histogram-based-feature skewness

Comparison of non-dysplastic crypts (NM) to dysplastic crypts (CAD). a) 8-bit images, b) respective histograms, c) results of histogram-based features

Normal mucosa (NM), 8-bit $\quad$ Classical adenoma (CAD), 8-bit

a)
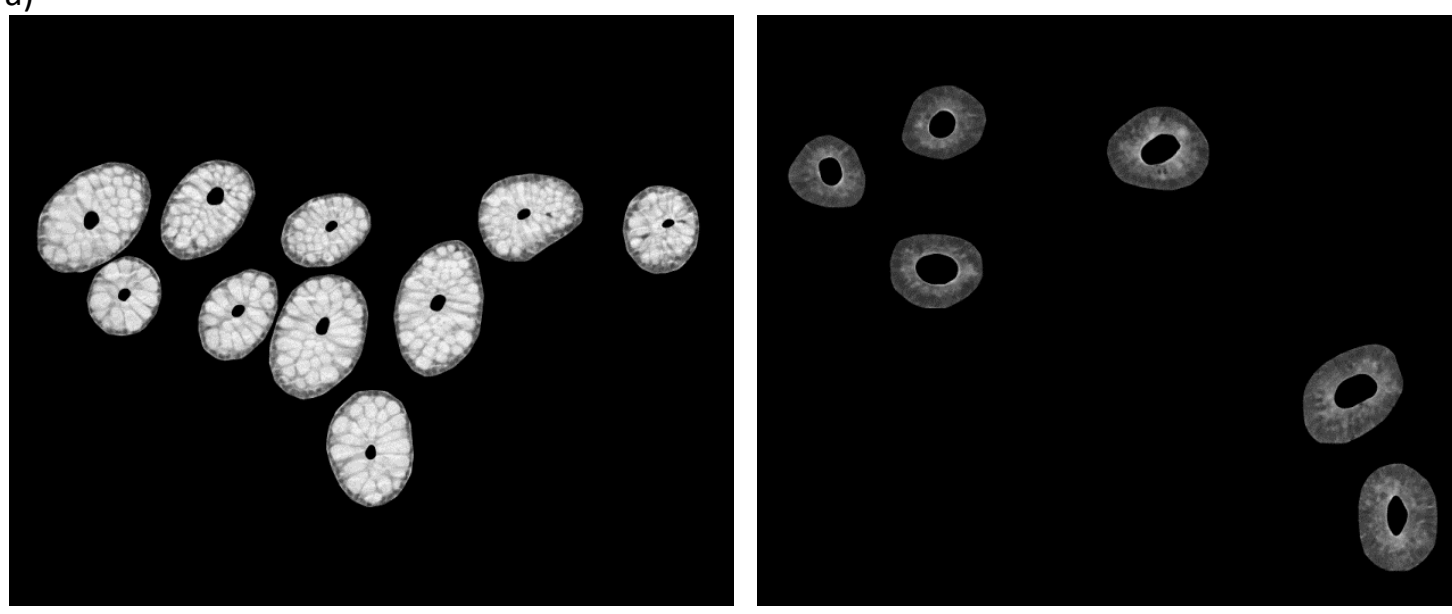

b)
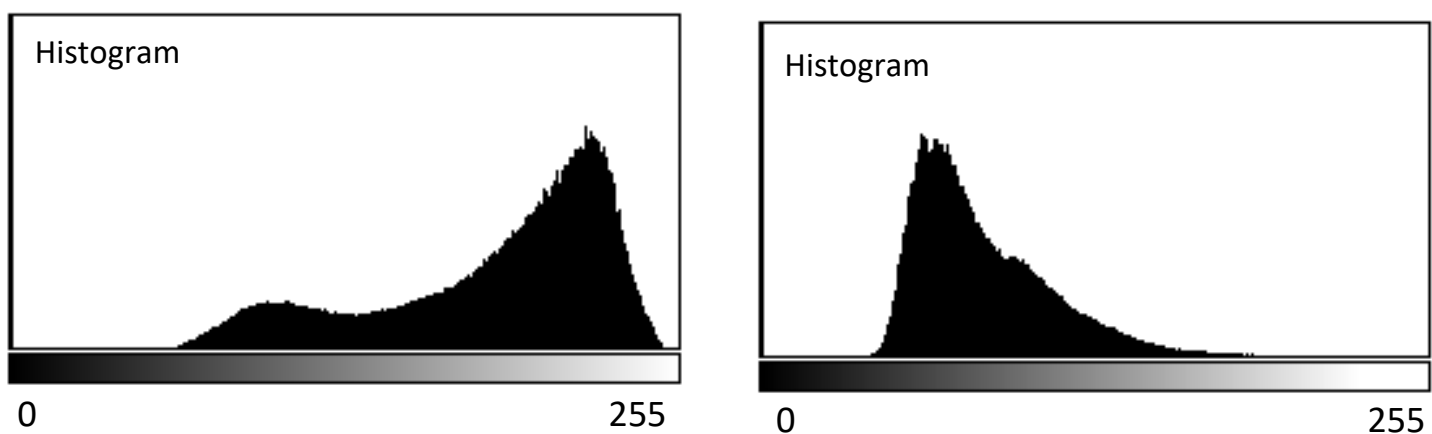

c)

\begin{tabular}{ll}
\hline Parameter & Value \\
\hline Mean & 184.34 \\
Skewness & -0.91 (left-tailed) \\
Kurtosis & -0.205 \\
\hline
\end{tabular}

\begin{tabular}{ll}
\hline Parameter & Value \\
\hline Mean & 84.67 \\
Skewness & 1.26 (right-tailed) \\
Kurtosis & 1.85 \\
\hline
\end{tabular}




\subsubsection{Cut-offs for serration and cytological dysplasia}

The optimal threshold value is computed based on the receiver operating characteristic curve (ROC curve). These cut-offs are extracted for all examined parameters concerning shape factors and histogram-based features. The overall accuracy (OAA) retrieved from the confusion matrix

is then determined (OAA $=\frac{\sum_{i=1}^{r} n_{i i}}{n}$, with $r$ number of classes, $n$ number of all classified crypts, $n_{i i}$ correctly classified crypts).

Suitable parameters and cut-offs that are received from the training data set, are then applied on the test data set. Afterwards, we use the parameters on data set III measuring serration in the basal part of the crypt and its referring apical part to see in which way the degree of serration differs in these two areas.

\subsection{Results and Discussion}

In this chapter, first, it is shown which shape descriptors describe precisely serration of crypt lumen. Second, it is presented which histogram-based features are adequate for characterization and differentiation of cytological dysplasia. The selected features are then applied on the test data set. Furthermore, these features are applied on another data set (referred to as Data Set III) sub-dividing the crypt in an upper and lower part to distinguish the degree of serration within the crypt. In the last subchapter, results and theses postulated in chapter 2.1.4 are discussed.

\subsubsection{Suitable geometric features for describing serration}

The shape factors mentioned in subchapter 2.3.1 are applied on the digitalized training data set. The four best results are shown in Figure 7. The best result is achieved for the shape factor solidity. On the reference data set, non-serrated crypt lumina could be differentiated from serrated crypt lumina with an accuracy of $100 \%$. The cut-off was at 0.87 . (Range: NM 0.92 to 0.98 , CAD 0.88 to 0.99 , HP 0.44 to 0.83 , SSA 0.48 to 0.86 ). Next to solidity, the feature circularity shows a good differentiation between non-serrated and serrated crypt lumina (Accuracy $=0.97$ ). Both, solidity and circularity are good measures for irregularity.

The shape factor area ratio describes the relation of the lumen area to the crypt area. It divides non-serrated crypts from serrated crypts with an accuracy of $94 \%$. In case of nonserrated crypts (NM, CAD), the area ratio achieves lower values than the one of serrated crypts (HP, SSA). It shows that the percentage of lumen area within the crypt itself is smaller for nonserrated crypts than for serrated crypts (Range: NM 0.01 to 0.11 , CAD 0.02 to 0.24 , HP 0.11 to 0.43 , SSA 0.17 to 0.38 ). The perimeter of lumen area is higher for serrated crypt lumina than for non-serrated ones. A differentiation of the two classes can be achieved with an accuracy of $94 \%$. A disadvantage is the value range of this perimeter since the upper value is unlimited. Therefore, 
it is reasonable to relate this factor to e.g. its area as it is done in the feature circularity or roundness. In Table 11, overall accuracies for all shape factors are presented.

Figure 7: Illustration of shape descriptor results (training data)

Boxplots for the classes NM, CAD, HP and SSA according to the shape descriptors solidity, circularity, area ratio and perimeter lumen.
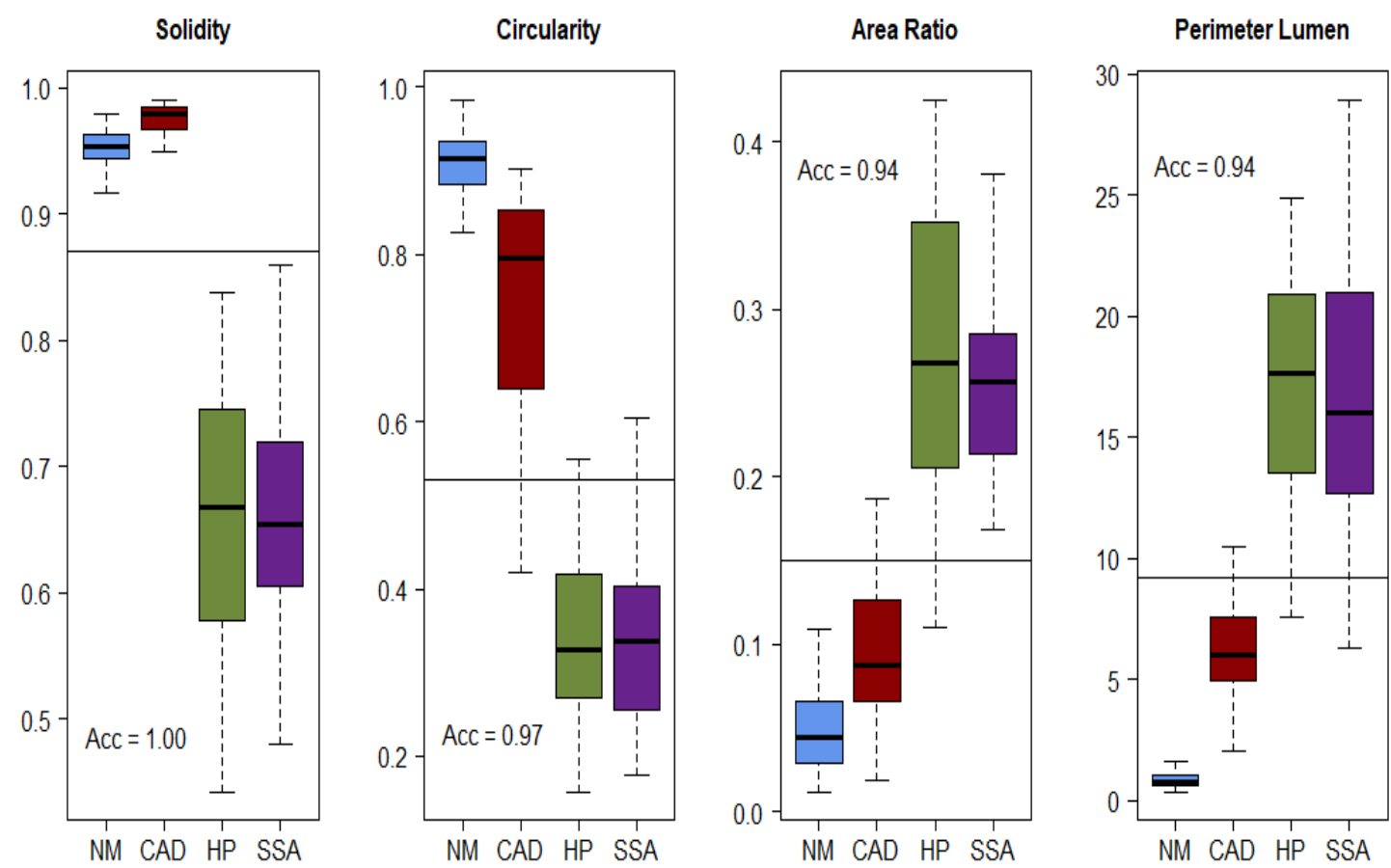

Table 11: Overall Accuracy results for shape descriptors

Overall accuracy results with which non-serrated crypts from serrated ones are divided based on all nine shape factors for training data and selected shape factors for test data.

\begin{tabular}{lcc}
\hline Parameter & OAA (training data) & OAA (test data) \\
\hline Solidity & 1.00 & 0.97 \\
Circularity & 0.97 & 0.91 \\
Area Ratio & 0.94 & 0.94 \\
Perimeter Lumen & 0.94 & - \\
Area Lumen & 0.88 & - \\
Major axis & 0.87 & - \\
Minor axis & 0.87 & - \\
Aspect Ratio & 0.65 & - \\
Roundness & 0.65 & - \\
\hline
\end{tabular}

The thresholds of the best three shape descriptors solidity (threshold $=0.87$ ), circularity (threshold $=0.53$ ) and area ratio (threshold $=0.15$ ) determined in the training data set are then applied to the test data set (see also Table 11). Again, the shape descriptor solidity achieves the best result with an overall accuracy of $97 \%$. The results are also illustrated in Figure 8 . 
Figure 8: Illustration of shape descriptor results (test data)

Boxplots for the classes NM, CAD, HP and SSA according to the shape descriptors solidity, circularity and area ratio.
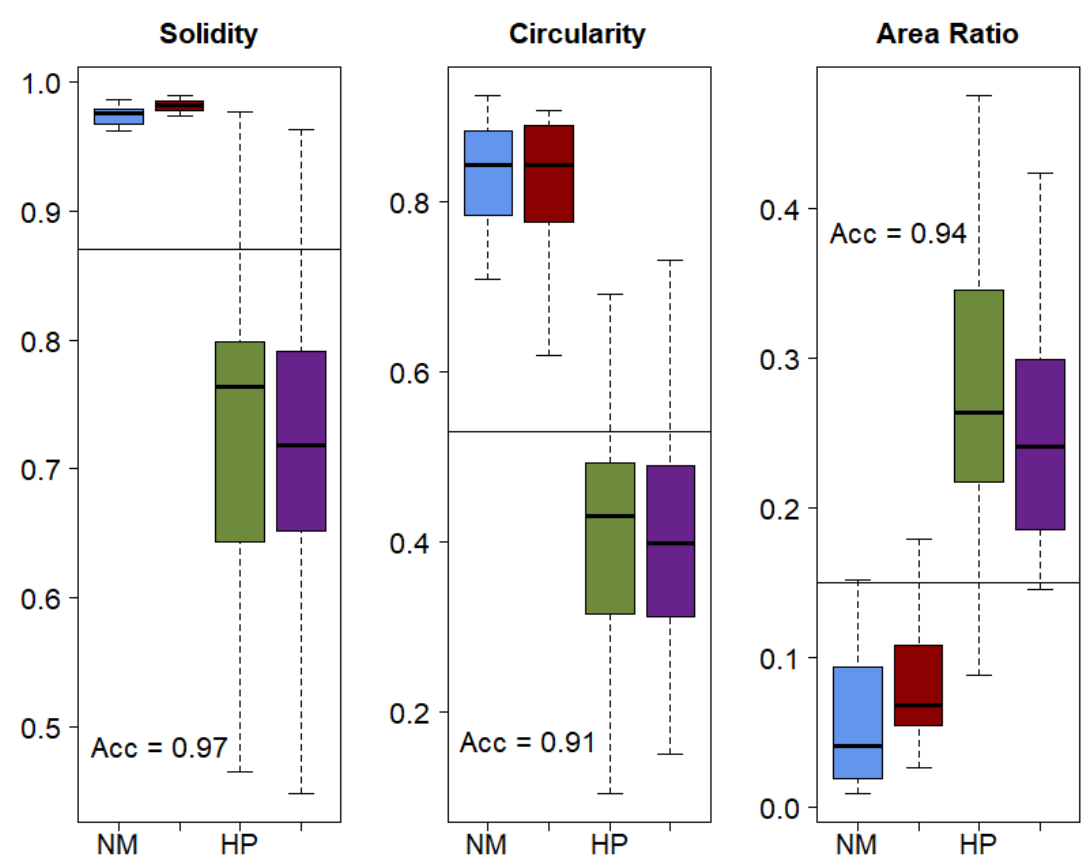

\subsubsection{Suitable histogram-based features for describing cytological dysplasia}

For describing cytological dysplasia, the histogram-based features presented in subchapter 2.3.2 are applied on the training data set. In Figure 9, the best results are shown for distinguishing non-dysplastic crypts from dysplastic ones. The best result is achieved with the feature skewness on the blue channel with an accuracy of $93 \%$, closely followed by the feature skewness on the brightness channel. Furthermore, the mode divides the two classes with an accuracy of $89 \%$. In Table 12, a subset of overall accuracies of histogram-based features are shown on different channels. The best results are marked with bold numbers (skewness - blue channel: 0.93; skewness - brightness channel: 0.90; mode - gray channel: 0.90; mode - blue channel: 0.89) 
Figure 9: Illustration of histogram-based feature results (training data) Boxplots for the classes NM and CAD according to the histogram-based features skewness and mode on the gray, blue and brightness channel.
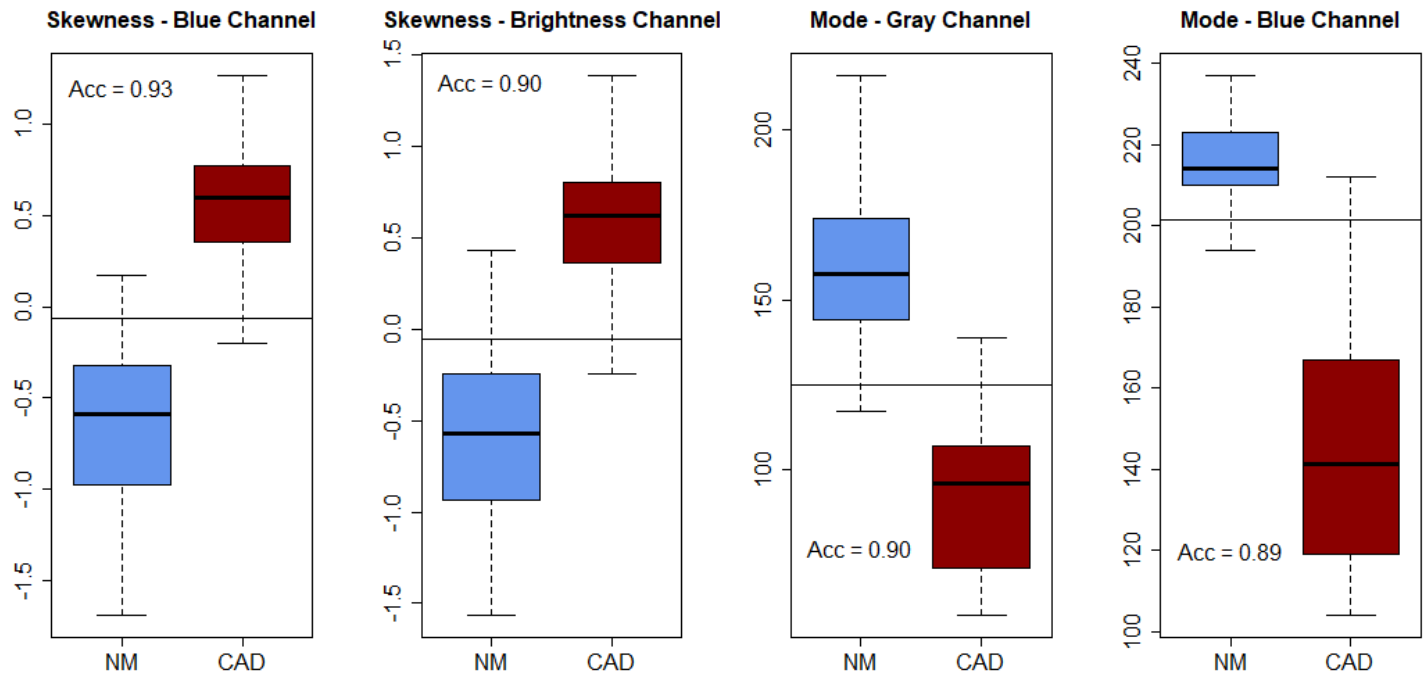

Table 12: Overall Accuracy results for histogram-based features (training data)

Overall Accuracy results with which non-dysplastic crypts from dysplastic ones are divided based on 4 different histogram-based features on 6 different channels.

\begin{tabular}{lcccccc}
\hline \multicolumn{7}{c}{ Overall Accuracy according to respective channel } \\
Parameter & Gray & Red & Green & Blue & Saturation & Brightness \\
\hline Mean & 0.83 & 0.74 & 0.84 & 0.84 & 0.83 & 0.84 \\
Mode & $\mathbf{0 . 9 0}$ & 0.73 & 0.80 & $\mathbf{0 . 8 9}$ & 0.86 & 0.78 \\
Skewness & 0.76 & 0.68 & 0.80 & $\mathbf{0 . 9 3}$ & 0.71 & $\mathbf{0 . 9 0}$ \\
Kurtosis & 0.62 & 0.53 & 0.78 & 0.52 & 0.71 & 0.5 \\
\hline
\end{tabular}

Next, we apply the best-found histogram-based features to the test data set. Overall Accuracy results are shown in Figure 10. It is already seen, that accuracy results are not consistent with the results on the training data set. This issue will be discussed in the next paragraph. 
Figure 10: Illustration of histogram-based feature results (test data)

Boxplots for the classes NM and CAD according to the histogram-based features skewness and mode on the gray, blue and brightness channel. Boxplots and the table show overall accuracy.
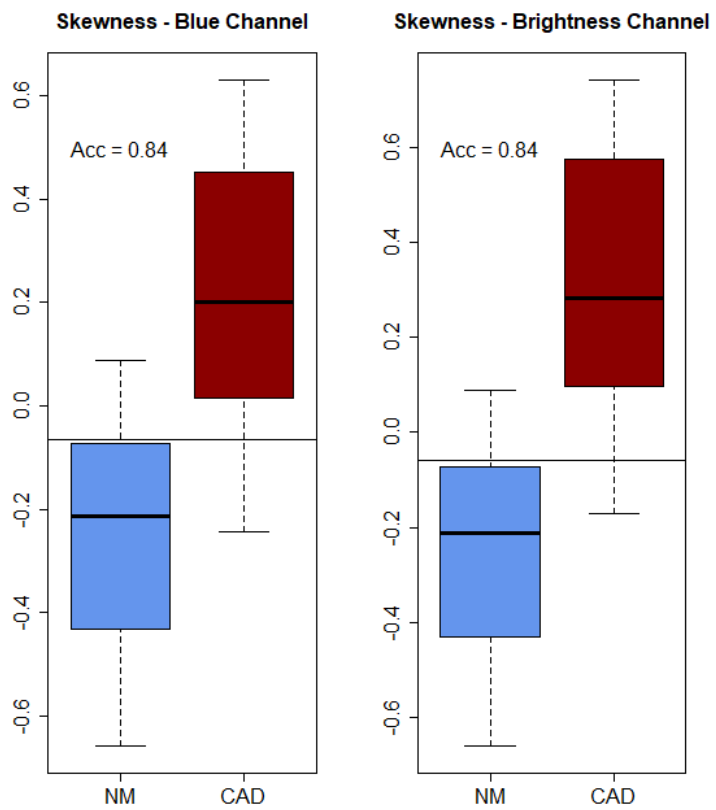

\begin{tabular}{ll}
\hline Parameter - Channel & Acc. \\
\hline Skewness - Blue & 0.84 \\
Skewness - Brightness & 0.84 \\
\hline
\end{tabular}

\subsubsection{Discussion of postulated theses}

In Figure 7, it is seen that the shape factor solidity distinguishes non-serrated from serrated crypts with the highest overall accuracy. This is plausible, since the solidity parameter is sensitive to irregular borders and therefore a good method to describe serration. It proves our first thesis that serration of crypt lumen can be described precisely by geometrical features. The best cut-off is found at 0.87 . In Figure 9, the best result for cytological dysplasia differentiation is shown. The skewness parameter is found as the best parameter to distinguish non-dysplastic from dysplastic crypts reaching an overall accuracy of 0.93 . When skewness is less than 0 , the histogram shows a left-tailed distribution. Hence, there are more pixels in the crypt that have brighter than darker values, which in case of NM is reasonable, since the nucleus-cytoplasm ratio favors the "brighter" cytoplasm. When skewness is greater than 0 , the issue is the opposite and is also plausible since the nucleus-cytoplasm ratio favors the "darker" nuclei. This parameter works best on the blue channel due to the bluish staining of cell nuclei. This proves our second thesis that cytological dysplasia can be characterized and differentiated by histogram-based features. As a consequence, our first thesis is confirmed, as the overall accuracy for the classification of healthy tissue, non-serrated lesions, and serrated lesions is 0.93 . 


\subsubsection{Application of selected feature cut-offs to test data}

Another question that arises is, are the parameters applicable on different data sets? Therefore, we employ the chosen features and its cut-offs on a test data set. It is seen, that the feature solidity also achieves a high overall accuracy result $(A c c=0.97)$. Thus, we presume that this feature might be used in a greater context, still achieving robust and precise results distinguishing non-serrated from serrated crypts. Concerning histogram-based features, the accuracy rate on the training data set is 0.93 and on the test data set 0.84 . Here, there is a better differentiation of non-dysplastic and dysplastic crypts desirable. Since histogram-based features depend on different factors such as illumination, staining, etc. image pre-processing is reasonable in a follow-up.

\subsubsection{Differentiation of serration within the crypt}

Besides the question, if the selected parameters and cut-offs can be used on diverse data sets, we also investigate if there are differences in the degree of serration within the crypt. For example, experts in GI pathology observed, that hyperplastic polyps (HP) don't express serration in the lower part of the crypt but is well-expressed in the upper half. Thus, we used a data set, in which crypts were sub-divided in the lower part (crypt at base) and the upper part (crypt at surface) (see also chapter 2.2.3).

In Figure 11, the results are shown for the classes CAD, HP, SSA, SSAD and TSA. The cut-off value obtained from the training data set divides crypt lumina in non-serrated and serrated lumina. Values greater than 0.87 are classified as "non-serrated crypts", values less than 0.87 as "serrated crypts". The majority of crypt lumina that are non-serrated occur in the class CAD. HP shows a high amount of non-serrated crypts, but only in the basal part. This confirms the observation that in HP serration is more pronounced in the upper half of the crypt than in the lower part $[42,43]$. Comparing the two classes SSA and SSAD it is seen that the degree of serration declines from SSA to SSAD validating the observation that serration diminishes when cytological dysplasia is pronounced in SSA. TSA shows very low values of solidity confirming the process of hyperserration [42]. 
Figure 11: Solidity results, subdivided into crypts at base and at surface (Data Set III)

Top Boxplots showing values of solidity, classes CAD, HP, SSA, SSAD, TSA, further subdivided into crypts at base $\left(=\mathrm{X} \_\mathrm{b}\right)$ and at surface $\left(=\mathrm{X} \_\mathrm{s}\right)$. Bottom Classification assignment using previously computed cut-off.

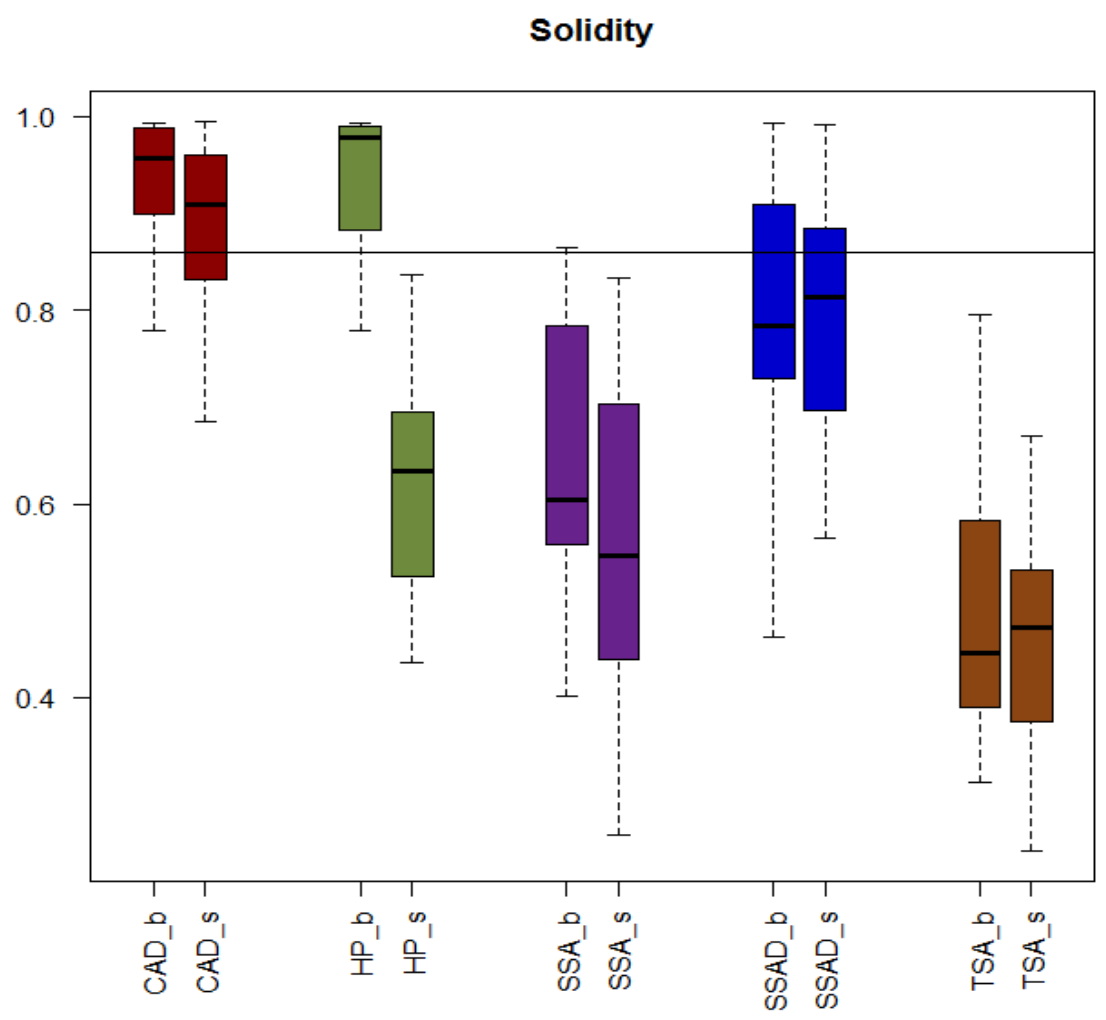

\begin{tabular}{lcc}
\hline & \multicolumn{2}{c}{ Classification Assignment } \\
& serrated & non-serrated \\
\hline CAD_b & 0.12 & $\mathbf{0 . 8 8}$ \\
CAD_S & 0.40 & $\mathbf{0 . 6 0}$ \\
HP_b & 0.20 & $\mathbf{0 . 8 0}$ \\
HP_S & $\mathbf{1 . 0 0}$ & 0.00 \\
SSA_b & $\mathbf{0 . 9 6}$ & 0.04 \\
SSA_S & $\mathbf{1 . 0 0}$ & 0.00 \\
SSAD_b & $\mathbf{0 . 6 4}$ & 0.36 \\
SSAD_S & $\mathbf{0 . 6 4}$ & 0.36 \\
TSA_b & $\mathbf{1 . 0 0}$ & 0.00 \\
TSA_S & $\mathbf{1 . 0 0}$ & 0.00 \\
\hline
\end{tabular}

\subsection{Conclusion and Outlook}

In this study, we evaluated and demonstrated which features are applicable for an automated characterization and classification of colorectal polyps on digitized histological slides. This approach can be integrated in the larger context of computer-aided pre-screening and classification which is increasingly important since colonoscopy screening is a worldwide and frequently applied procedure in medicine. Furthermore, processes such as the loss of serration 
or change in distribution of serration can be measured reproducibly and precisely with the previously mentioned features confirming processes already mentioned in literature and being essential for understanding underlying mechanisms in precursor lesions.

In case of describing cytological dysplasia, good results are achieved but are not comparable to the high overall accuracy results of describing serration in a robust and precise way. Therefore, further investigation e. g. concerning image pre-processing is important in the followup to achieve better results for characterizing cytological dysplasia. 


\subsection{Reference list}

[1] P. W. Hamilton, P. Bankhead, Y. Wang, R. Hutchinson, D. Kieran, D. G. McArt, J. James and M. Salto-Tellez, "Digital pathology and image analysis in tissue biomarker research," Methods, vol. 70, no. 1, pp. 59-73, 2014.

[2] A. Ensari, B. Bilezikçi, F. Carneiro, G. B. Dogusoy, A. Driessen, A. Dursun, J.-F. Flejou, K. Geboes, G. de Hertogh, A. Jouret-Mourin, C. Langner, I. D. Nagtegaal, J. Offerhaus, J. Orlowska, A. Ristimäki, J. Sanz-Ortega, B. Savas, M. Sotiropoulou, V. Villanacci, N. Kursun, F. Bosman and G. B. Doğusoy, "Serrated polyps of the colon: how reproducible is their classification?," Virchows Arch, vol. 461, pp. 495-504, 2012.

[3] T. T. Rau, A. Agaimy, A. Gehoff, C. Geppert, K. Jung, K. Knobloch, C. Langner, A. Luigi, I. Groenbus-Lurkin, I. Nagtegaal, J. Rüschoff, X. Saegert, M. Sarbia, R. Schneider-Stock, M. Vieth, E. C. Zwarthoff and A. Hartmann, "Defined morphological criteria allow reliable diagnosis of colorectal serrated polyps and predict polyp genetics," Virchows Arch, vol. 464, no. 6, pp. 663-72, June 2014.

[4] K. Sirinukunwattana, J. Pluim, H. Chen, X. Qi, P.-A. Heng, Y. B. Guo, L. Y. Wang, B. J. Matuszewski, E. Bruni, U. Sanchez, A. Böhm, O. Ronneberger, B. B. Cheikh, D. Racoceanu, P. Kainz, M. Pfeiffer, M. Urschler, D. Snead and N. M. Rajpoot, "Gland segmentation in colon histology images: The glas challenge contest," Medical Image Analysis, vol. 35, pp. 489-502, January 2017.

[5] F. A. Haggar and R. P. Boushey, "Colorectal Cancer Epidemiology: Incidence, Mortality, Survival, and Risk Factors," Clin Colon Rectal Surg, vol. 22, no. 4, pp. 191-197, 2009.

[6] A. G. Zauber, S. J. Winawer, M. J. O'Brien, I. Lansdorp-Vogelaar, M. Van Ballegooijen, B. F. Hankey, W. Shi, J. H. Bond, M. Schapiro, J. F. Panish, E. T. Stewart and J. D. Waye, "Colonoscopic Polypectomy and Long-Term Prevention of Colorectal Cancer Deaths," $N$ Engl J Med, vol. 366, no. 8, pp. 687-696, 2012.

[7] A. Giacosa, F. Frascio and F. Munizzi, "Epidemiology of colorectal polyps.," Tech Coloproctol, vol. 8, pp. 243-247, 2004.

[8] V. Conteduca, D. Sansonno, S. Russi and F. Dammaco, "Precancerous colorectal lesions (Review).," Int J Oncol, vol. 43, no. 4, pp. 973-984, 2013.

[9] R. D. Odze and J. R. Goldblum, Surgical Pathology of the Gl tract, liver, biliary tract, and pancreas, Philadelphia: Elsevier Saunders, 2015.

[10] G. A. Colditz, K. A. Atwood, K. Emmons, R. R. Monson, W. C. Willett, D. Trichopoulos and D. J. Hunter, "Harvard report on cancer prevention volume 4: Harvard Cancer Risk Index. 
Risk Index Working Group, Harvard Center for Cancer Prevention.," Cancer Causes Control, vol. 11, no. 6, pp. 477-488, 2000.

[11] E. R. Fearon and B. Vogelstein, "A genetic model for colorectal tumorigenesis," Cell, vol. 61, pp. 759-767, 1990.

[12] N. J. Hawkins, C. Bariol and R. L. Ward, "The serrated neoplasia pathway.," Pathology, vol. 34, no. 6, pp. 548-555, 2002.

[13] J. R. Jass, "Serrated route to colorectal cancer: back street or super highway?," J Pathol, vol. 193, no. 3, pp. 283-285, 2001.

[14] K. Oh, M. Redstone and R. D. Odze, "Support for hMLH1 and MGMT silencing as a mechanism of tumorigenesis in the hyperplastic-adenoma-carcinoma (serrated) carcinogenic pathway in the colon.," Hum Pathol, vol. 36, no. 1, pp. 101-111, 2005.

[15] Y. Sucaet and W. Waelput, Digital Pathology, Cham: Springer International Publishing, 2014.

[16] J. Griffin and D. Treanor, "Digital pathology in clincal use: where are we now and what is holding us back?," Histopathology, vol. 70, no. 1, pp. 134-145, 2017.

[17] R. S. Weinstein, A. R. Graham, F. Lian, B. L. Braunhut, G. R. Barker, E. A. Krupinski and A. K. Bhattacharyya, "Reconciliation of diverse telepathology system designs. Historic issues and implications for emerging markets and new applications," APMIS, vol. 120, no. 4, pp. 256-275, 2012.

[18] P. W. Hamilton, Y. Wang, C. Boyd, J. A. James, M. B. Loughrey, J. P. Hougton, D. P. Boyle, P. Kelly, P. Maxwell, D. McCleary, J. Diamond, D. G. McArt, J. Tunstall, P. Bankhead and M. Salto-Tellez, "Automated tumor analysis for molecular profiling in lung cancer," Oncotarget, vol. 6, no. 29, pp. 27938-27952, 2015.

[19] A. Madabhushi and G. Lee, "Image analysis and machine learning in digital pathology: Challenges and opportunities," Med Image Anal, vol. 33, pp. 170-175, 2016.

[20] P. W. Hamilton, P. J. Van Diest, R. Williams and A. G. Gallagher, "Do we see what we think we see? The complexities of morphological assessment.," J Pathol., vol. 218, no. 3, pp. 285-291, 2009.

[21] H. Fatakdawala, J. Xu, A. Basavanhally, G. Bhanot, S. Ganesan, M. Feldmann, J. E. Tomaszewski and A. Madabhushi, "Expectation-maximization-driven geodesic active contour with overlap resolution (EMaGACOR): application to lymphocyte segmentation on breast cancer histopathology.," IEEE Trans Biomed Eng, vol. 57, no. 7, pp. 1676-89, 2010.

[22] D. Glotsos, P. Spyridonos, D. Cavouras, P. Ravazoula, P. A. Dadioti and G. Nikiforidis, "Automated segmentation of routinely hematoxylin-eosin-stained microscopic images by 
combining support vector machine clustering and active contour models.," Anal Quant Cytol Histol, vol. 26, no. 6, pp. 331-340, 2004.

[23] K. Sirinukunwattana, D. R. Snead and N. M. Rajpoot, "A Stochastic Polygons Model for Glandular Structures in Colon Histology Images.," IEEE Trans Med Imaging, vol. 34, no. 11, pp. 2366-78, 2015.

[24] K. Sirinukunwattana, S. Raza, Y.-W. Tsang, D. Snead, I. Cree and N. Rajpoot, "Locality Sensitive Deep Learning for Detection and Classification of Nuclei in Routine Colon Cancer Histology Images.," IEEE Trans Med Imaging, vol. 35, no. 5, pp. 1196-1206, 2016.

[25] A. E. Carpenter, T. R. Jones, M. R. Lamprecht, C. Clarke, I. H. Kang, O. Friman, D. A. Guertin, J. H. Chang, R. A. Lindquist, J. Moffat, P. Golland and D. M. Sabatini, "CellProfiler: image analysis software for identifying and quantifying cell phenotypes.," Genome Biol, vol. 7, no. 10, 2006.

[26] P. Bankhead, M. B. Loughrey, J. A. Fernández, Y. Dombrowski, D. G. McArt, P. D. Dunne, S. McQuaid, R. T. Gray, L. J. Murray, H. G. Coleman, J. A. James, M. Salto-Tellez and P. W. Hamilton, "QuPath: Open source software for digital pathology image analysis," Scientific Reports, vol. 7, 2017.

[27] R. Jain, R. Kasturi, G. Brian and B. G. Schunck, Machine Vision, New York: McGraw-Hill, 1995.

[28] J. P. Baak, H. Van Dop, P. H. Kurver and J. Hermans, "The value of morphometry to classic prognosticators in breast cancer.," Cancer, vol. 56, no. 2, pp. 374-382, 1985.

[29] J. M. Dunn, G. D. Mackenzie, D. Oukrif, C. A. Mosse, M. R. Banks, S. Thorpe, P. Sasieni, S. G. Bown, M. R. Novelli, P. S. Rabinovitch and L. B. Lovat, "Image cytometry accurately detects DNA ploidy abnormalities and predicts late relapse to high-grade dysplasia and adenocarcinoma in Barrett's oesophagus following photodynamic therapy.," Br J Cancer, vol. 102, no. 11, pp. 1608-17, 2010.

[30] A. Bosch, X. Munoz and R. Martí, "Which is the best way to organize/classify images by content?," Image Vision Comput, vol. 25, no. 6, pp. 778-791, 2007.

[31] J. C. Caicedo, F. A. González and E. Romero, "Content-based histopathology image retrieval using a kernel-based semantic annotation framework.," J Biomed Informatics, vol. 44, no. 4, pp. 519-528, 2011.

[32] C. Münzenmayer, T. Schlarb, D. Steckhan, E. Haßlmeyer, T. Bergen, S. Aschenbrenner, T. Wittenberg, C. Weigand and T. Zerfaß, "HemaCAM - A Computer Assisted Microscopy System for Hematology.," in Microelectronic Systems, Springer Verlag, 2011, pp. 233-242.

[33] S. Krappe, T. Wittenberg, T. Haferlach and C. Münzenmayer, "Automated morphological analysis of bone marrow cells in microscopic images for diagnosis of leukemia: Nucleus- 
plasma separation and cell classification using a hierarchical tree model of hematopoesis," in Proceedings of SPIE 9785, San Diego, 2016.

[34] K. Jafari-Khouzani and H. Soltanian-Zadeh, "Multiwavelet grading of pathological images of prostate.," IEEE Trans Biomed Eng, vol. 50, no. 6, pp. 697-704, 2003.

[35] G. Lee, R. Sparks, S. Ali, N. N. Shih, M. D. Feldmann, E. Spangler, T. Rebbeck, J. E. Tomaszewski and A. Madabhushi, "Co-occurring gland angularity in localized subgraphs: predicting biochemical recurrence in intermediate-risk prostate cancer patients.," PLOS One, vol. 9, no. 5, 2014.

[36] M. G. Ertosun and D. L. Rubin, "Automated Grading of Gliomas using Deep Learning in Digital Pathology Images: A modular approach with ensemble of convolutional neural networks.," AMIA Annu Symp Proc, pp. 1899-1908.

[37] X. Y. Wang, D. Zuo, D. Sarkar and P. B. Fisher, "Blockade of cytotoxic T-lymphocyte antigen-4 as anew therapeutic approach for advanced melanoma.," Expert Opin Pharmacother, vol. 12, no. 17, pp. 2695-706, 2011.

[38] D. Gancberg, T. Järvinen, A. Di Leo, G. Rouas, F. Cardoso, M. Paesmans, A. Verhest, M. J. Piccart, J. Isola and D. Larsimont, "Evaluation of HER-2/NEU protein expression in breast cancer by immunohistochemistry: an interlaboratory study assessing the reproducibility of HER-2/NEU testing.," vol. 74, no. 2, pp. 113-120, 2002.

[39] A. Rhodes, B. Jasani, A. J. Balaton, D. M. Barnes, E. Anderson, L. G. Bobrow and K. D. Miller, "Study of interlaboratory reliability and reproducibility of estrogen and progesterone receptor assays in Europe.," Am J Clin Pathol, vol. 115, no. 1, pp. 44-58, 2001.

[40] J. Dennis, R. Parsa, D. Chau, P. Koduru, Y. Peng, Y. Fang and V. R. Sarode, "Quantification of human epidermal growth factor receptor 2 immunohistochemistry using Ventana Image Analysis System: correlation with gene amplification by fluorescence in situ hybridization," Am J Surg Patholog, vol. 39, no. 5, pp. 624 - 631, 2015.

[41] L. M. McShane, R. Aamodt, C. Cordon-Cardo, R. Cote, D. Faraggi, Y. Fradet, H. B. Grossmann, A. Peng, S. E. Taube and F. M. Waldmann, "Reproducibility of p53 immunohistochemistry in bladder tumors. National Cancer Institute, Bladder Tumor Marker Network.," Clin Cancer Res, vol. 6, no. 5, pp. 1854-64, 2000.

[42] M. Y. Polley, S. C. Leung, L. M. McShane, D. Gao, J. C. Hugh, M. G. Mastropasqua, G. Viale, L. A. Zabaglo, F. Penault-Llorca, J. M. Bartlett, A. M. Gown, W. F. Symmans, T. Piper, E. Mehl, R. A. Enos, D. F. Hayes, M. Dowsett and T. O. Nielsen, "An international Ki67 reproducibility study.," J Nat/ Cancer Inst, vol. 105, no. 24, pp. 1897-906, 2013.

[43] F. Klauschen, S. Wienert, W. D. Schmitt, S. Loibl, B. Gerber, J. Blohmer, J. Huober, T. Rüdiger, E. Erbstößer, K. Mehta, B. Lederer, M. Dietel, C. Denkert and G. Von Minckwitz, 
"Standardized Ki67 Diagnostics Using Automated Scoring - Clinical Validation in the GeparTrio Breast Cancer Study," Clin Cancer Res, vol. 21, no. 16, pp. 3651-3657, 2015.

[44] D. C. Snover, D. J. Ahnen, R. W. Burt and R. D. Odze, "Serrated polyps of the colon and rectum and serrated polyposis," in WHO classification of tumours of the digestive system, 2010, pp. $160-165$.

[45] D. K. Rex, D. J. Ahnen, J. A. Baron, K. P. Batts, C. A. Burke, R. W. Burt, J. R. Goldblum, J. G. Guillem, C. J. Kahi, M. F. Kalady, M. J. O'Brien, R. D. Odze, S. Ogino, S. Parry, D. C. Snover, E. E. Torlakovic, P. E. Wise, J. Young and J. Church, "Serrated lesions of the colorectum: Review and Recommendations from an expert panel," The American Journal of gastroenterology, vol. 107, no. 9, pp. 1315-1329, 2012.

[46] R. S. Weinstein, K. J. Bloom and L. S. Rozek, "Telepathology and the networking of pathology diagnostic services," Arch. Pathol. Lab. Med., vol. 111, pp. 646-652, 1987. 


\subsection{Appendix}

\subsubsection{Abbreviations}

CAD

Classic adenoma

CRC

Colorectal cancer

DP

Digital pathology

HP

Hyperplastic polyp

$\mathrm{IHC}$

Immunhistochemistry

NM

Normal mucosa

MIT

Mixed-type polyp

OAA

Overall Accuracy

ROC

receiver operating characteristic

SSA

Sessile serrated adenoma

SSAD

Sessile serrated adenoma with dysplasia

TSA

Traditional serrated adenoma

WHO

World Health Organization

WSI

Whole Slide Imaging 


\subsubsection{Figures}

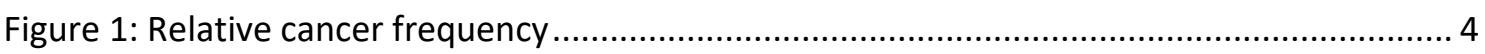

Figure 2: Concept of WSI-enhanced dynamic-robotic telepathology....................................... 7

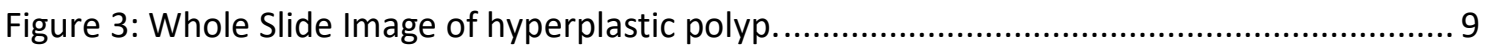

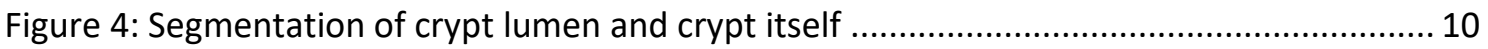

Figure 5: Decision Tree of colorectal premalignant lesions ...................................................... 14

Figure 6: Descriptive statistic of classification results for Data Set I ....................................... 16

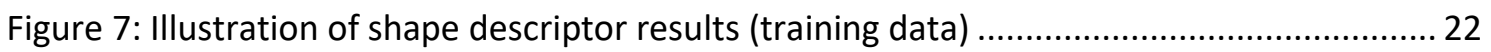

Figure 8: Illustration of shape descriptor results (test data)..................................................... 23

Figure 9: Illustration of histogram-based feature results (training data) ................................... 24

Figure 10: Illustration of histogram-based feature results (test data)....................................... 25

Figure 11: Solidity results, subdivided into crypts at base and at surface (Data Set III) ............. 27

\subsubsection{Tables}

Table 1: Risk Factors for Colorectal Cancer........................................................................... 5

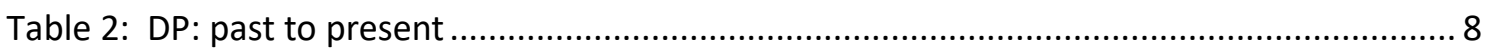

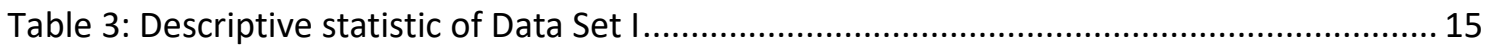

Table 4: Number of crypts and crypt lumina annotated in Data Set I and II. ............................ 17

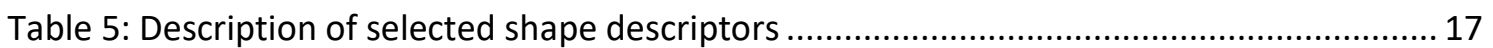

Table 6: Illustration of the feature solidity applied to an exemplary crypt lumen ..................... 18

Table 7: Results of shape descriptors for a non-serrated crypt compared to a serrated crypt.. 18

Table 8: Description of selected histogram-based features ....................................................... 19

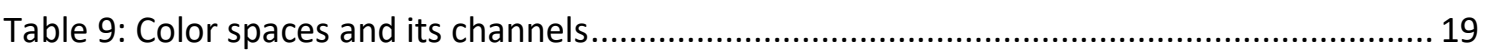

Table 10: Illustration of the histogram-based-feature skewness............................................... 20

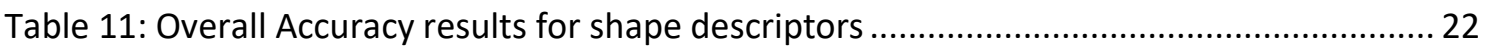

Table 12: Overall Accuracy results for histogram-based features (training data) ...................... 24 


\section{Thesis (original publication)}

In this chapter, the original publication is reprinted by permission from Springer as it was submitted to the journal Bildverarbeitung für die Medizin in 2016 in accordance with the journal's publication guidelines:

C. Dach, T. Rau, C. Geppert, A. Hartmann, T. Wittenberg, C. Münzenmayer, "Towards computerassisted diagnosis of precursor colorectal lesions" Bildverarbeitung für die Medizin, pp. 266-271, 2016. Springer-Verlag Berlin Heidelberg. 


\title{
Towards computer-assisted diagnosis of precursor colorectal lesions
}

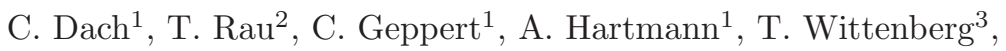 \\ C. Münzenmayer ${ }^{3}$ \\ ${ }^{1}$ Institute of Pathology, Friedrich-Alexander University, Erlangen-Nürnberg, Germany \\ ${ }^{2}$ Institute of Pathology, University of Bern, Bern, Switzerland \\ ${ }^{3}$ Fraunhofer Institute for Integrated Circuits IIS, Erlangen, Germany \\ claudia.dach@fau.de
}

\begin{abstract}
Colorectal cancer (CRC) is the fourth most common cancer in men worldwide (International Agency of Research on Cancer 2008). In many countries, regular colonoscopy screening is established as a crucial strategy for CRC prevention. During colonoscopy screening, detected precursor lesions such as adenomas and serrated polyps can be removed, thus reducing CRC incidence and mortality. After such a polypectomy, histological diagnosis is fundamental. With continuously rising numbers of participants in screening programs as well as removed polyps, an increased demand exists for an automated pre-screening and classification of colorectal lesions in digitized histological slides. Hence, in this study, initial experiments were conducted to evaluate which approaches are suitable for an automated pre-screening and classification of colorectal polyps into the known entities with different risk profiles. According to the latest WHO classification, key factors for distinguishing precursor lesions are serration, distribution of serration and cytological dysplasia. In this study, we investigate a learning scheme based on decision trees to identify image features, which precisely describe these key factors. It is shown that shape factors and histogram-based features extracted from digitized histological slides are suitable for computer-assisted pre-screening and classification of precursor colorectal lesions.
\end{abstract}

\section{Introduction}

Since the introduction of digital whole slide scanners, the research topic of digital pathology (DP) has been of growing interest. With continuously rising numbers of participants in colorectal screening programs as well as removed polyps, an increased demand exists for DP in terms of an automated pre-screening and classification of colorectal lesions in digitized histological slides. Image analysis that is based on nuclear morphometry and tissue architecture is a challenging, but promising field in DP. Diverse approaches were conducted on different tissues such as prostate or cervix [1]. In this study, we propose an initial interactive image analysis for precursor colorectal lesions by describing and distinguishing two significant processes occurring in such lesions: serration and cytological dysplasia. Describing serration is one important cue, since serration is related to 
the two broad pathways of colorectal carcinogenesis: the adenoma-carcinoma sequence and the more recently described serrated pathway. Hence, we examine if shape descriptors such as circularity, solidity, etc. are suitable for assessing the saw-toothed pattern of the white field area of the crypt also referred to as crypt lumen. A second important cue for classifying lesions is cytological dysplasia. In 2010, the WHO classified serrated colonic polyps into non-dysplastic and dysplastic [2]. Furthermore, non-serrated lesions such as classic adenomas can be distinguished from healthy tissue (normal mucosa) when cytological dysplasia is taken into account. Cytological dysplasia is very complex. It expresses changes in architecture, shape and color. We assume that changes, e.g. in nucleus-cytoplasm ratio, (pseudo-) stratification, hyperchromaticity (which are all features of cytological dysplasia) are connected to changes in color and color distribution within the affected area. Therefore, we investigate if histogram-based features are applicable to describe cytological dysplastic processes. In summary, we postulate and examine three theses

1. A tree classifier is able to distinguish between healthy tissue, classic adenomas, and serrated lesions.

2. Serration of crypt lumen can be described precisely by adequate geometrical features.

3. Cytological dysplasia of crypt can be characterized and differentiated by histogram-based features.

In Fig. 1, the decision tree visualizes the workflow and the underlying idea of this study: First, separating lesions into non-serrated and serrated, second, dividing lesions into non-dysplastic and dysplastic. In order to distinguish premalignant lesions from healthy tissue, normal mucosa (NM) is added in the diagram on the left side. In the class NM, neither serration nor cytological dysplasia is pronounced.

Fig. 1. Decision Tree of colorectal premalignant lesions on the basis of the WHO classification, 2010. On the left side, the class NM is added. NM=normal mucosa, $\mathrm{CAD}=$ classic adenoma, $\mathrm{HP}=$ hyperplastic polyp, $\mathrm{SSA}=$ sessile serrated adenoma without dysplasia, SSAD = SSA with dysplasia, TSA = traditional serrated adenoma.

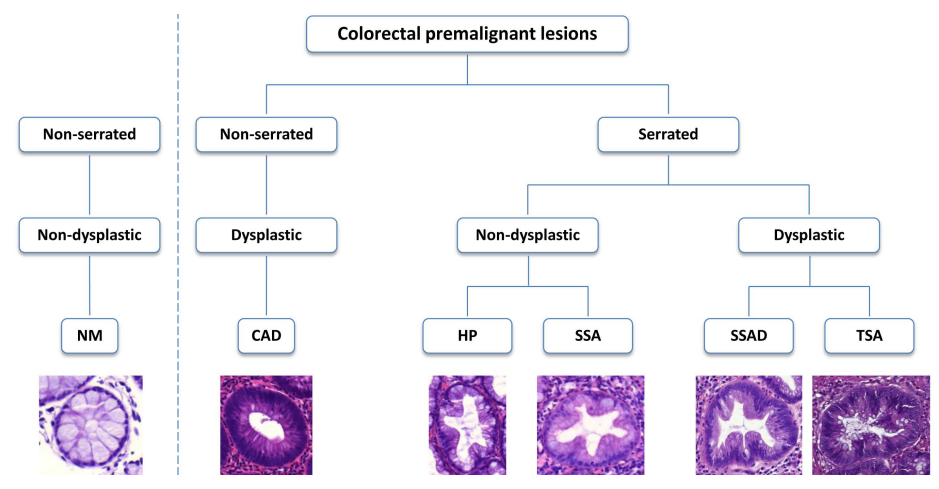


Table 1. Entities included in Data Set I and II as well as total number of crypts.

\begin{tabular}{lccccccc}
\hline & NM & CAD & HP & SSA & SSAD & TSA & \# crypts \\
\hline Data Set I & $\sqrt{ }$ & $\sqrt{ }$ & $\sqrt{ }$ & $\sqrt{ }$ & - & - & 200 \\
Data Set II & - & $\sqrt{ }$ & $\sqrt{ }$ & $\sqrt{ }$ & $\sqrt{ }$ & $\sqrt{ }$ & 250 \\
\hline
\end{tabular}

\section{Material and Methods}

\subsection{Material}

A reference image data set (referred to as Data Set I) was obtained from a previously conducted inter-observer study [3]. Ten experts, specialized in GI pathology, from all over Europe classified precursor lesions. Slides which all ten experts classified with the same diagnosis were included in the study. Two hundred crypts from 20 different cases were selected (see also Tab. 1). Crypt lumen and crypt itself were segmented using a semi-automatic approach. For lumen segmentation, a region-growing approach based on color and structure similarity was applied with manual seed points [4]; the crypt was segmented manually.

A second image data set (referred to as Data Set II) was provided from the Institute of Pathology, University of Bern, Switzerland, including cases of five different classes (see also Tab.1). In this collection, 125 basal crypts and its respective apical crypts from 25 different samples were marked by an expert for each class (basal referring to the lower half, apical to the upper half of the crypt).

\subsection{Methods}

To prove the first thesis (tree classification), a tree-based learning scheme is applied to identify suitable image features which separate NM, CAD, and serrated lesions. In the first level, crypts are classified into serrated and non-serrated. In the second level, dysplastic and non-dysplastic tissue is distinguished. The aim of this study is to identify image features, which are not only able to effectively characterize the given tissue, but which are also comprehensible for the pathologist. That way, we do not provide the clinician with a decision presented as a "black box", but we are able to provide objectively measured features. These relate to the key factors the pathologist is used to apply when assessing colorectal tissue. Thus, the goal is to find a single feature for each level of the decision tree and show its respective suitability to support the clinician's decision process.

In order to prove the second thesis (serration), Data Set I was used to find appropriate shape descriptors that distinguish precisely non-serrated from serrated crypt lumina. Based on the above mentioned interactive image annotation, a quantitative feature based analysis was conducted. As representative classes, we used NM and CAD for non-serrated crypts and HP and SSA for serrated crypts. Since serration can be assumed to be well-represented by the geometrical properties of the crypt lumina, nine established shape descriptors were evaluated including area, perimeter, area ratio $\frac{\text { Lumen Area }}{\text { Crypt Area }}$, major and minor axis of fitted 
ellipse, aspect ratio $\frac{\text { Major Axis }}{\text { Minor Axis }}$, circularity $\frac{4 \pi \cdot \text { Area }}{\text { Perimeter }^{2}}$, roundness $\frac{4 \cdot \text { Area }}{\pi \cdot \text { Major Axis }^{2}}$ and solidity $\frac{\text { Area }}{\text { Convex Area }}$.

To prove the third thesis (cytological dysplasia), Data Set I was used to evaluate if histogram-based features are an adequate approach to describe dysplasia distinguishing non-dysplastic from dysplastic crypts. As representative class, we used the class NM for non-dysplastic crypts and the class CAD for dysplastic crypts. Since dysplasia is assumed to express itself in a change of color, this differentiation was approached with histogram-based features such as mean, mode, min, max, variance, skewness and kurtosis, each obtained on different color channels (Gray, Red, Green, Blue, Hue, Saturation and Brightness).

The optimal threshold value was computed based on the receiver operating characteristic curve (ROC curve). These cut-offs were extracted for all examined parameters concerning shape factors and histogram-based features. The overall accuracy (OAA) retrieved from the confusion matrix was then determined (OAA $=\frac{\sum_{i=1}^{r} n_{i i}}{n}$, with $r$ number of classes, $n$ number of all classified crypts, $n_{i i}$ correctly classified crypts). All experiments were conducted using leaving-oneout cross validation.

Since not only serration itself, but also the distribution of serration are key factors for precursor lesions assessment, the parameters and cut-offs that were received from Data Set I (= reference data), were then applied on Data Set II. This time, we measured serration in the basal part of the crypt and its referring apical part to see in which way the degree of serration differs in these two areas.

\section{Results and Discussion}

In Fig. 2 (a, b), it is seen that the shape factor solidity distinguishes non-serrated from serrated crypts with the highest overall accuracy. This is plausible, since the solidity parameter is sensitive to irregular borders and therefore a good method to describe serration. It proves our second thesis that serration of crypt lumen can be described precisely by geometrical features. The best cut-off is found at 0.87. In Fig. 2 (c, d), the best result for dysplasia differentiation is shown. In this example, the skewness parameter is found as the best parameter to distinguish non-dysplastic from dysplastic crypts reaching an overall accuracy of 0.93 . When skewness is less than 0, the histogram shows a left-tailed distribution. Hence, there are more pixels in the crypt that have brighter than darker values, which in case of NM makes sense since the nucleus-cytoplasm ratio favors the "brighter" cytoplasm. When skewness is greater than 0, the issue is the opposite and is also plausible since the nucleus-cytoplasm ratio favors the "darker" nuclei. This parameter works best on the blue channel due to the bluish staining of cell nuclei. This proves our third thesis that cytological dysplasia can be characterized and differentiated by histogram-based features. As a consequence, our first thesis is confirmed, as the overall accuracy for the classification of healthy tissue, nonserrated lesions, and serrated lesions is 0.93 .

In Fig. 3, the degree of serration of basal crypts is compared to the one of apical crypts. The cut-off value obtained from Data Set I, divides crypt lumina 
Fig. 2. Results from Data Set I. a) Boxplots showing values of shape descriptor solidity, classes NM, CAD, HP and SSA. b) Overall Accuracy of best shape descriptors. c) Boxplots showing values of histogram-based feature skewness on blue channel, classes NM and CAD. d) Subset of Overall Accuracies of histogram-based features.

a)

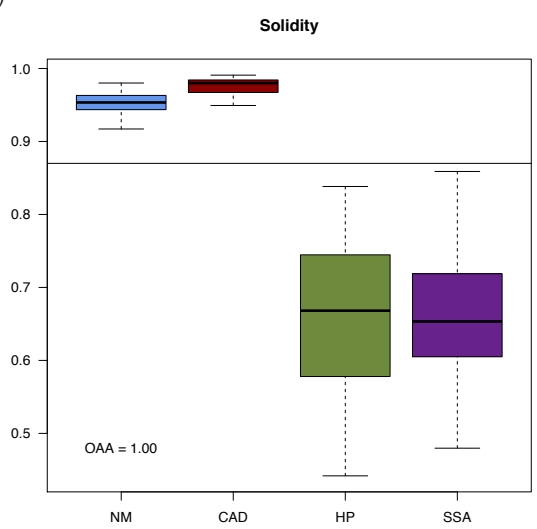

c)

\begin{tabular}{lc}
\hline Parameter & Overall Accuracy \\
\hline Area Lumen & 0.88 \\
Area Ratio & 0.94 \\
Perimeter Lumen & 0.94 \\
Major Axis & 0.87 \\
Minor Axis & 0.87 \\
Circularity & 0.97 \\
Solidity & $\mathbf{1 . 0 0}$ \\
\hline
\end{tabular}

b)

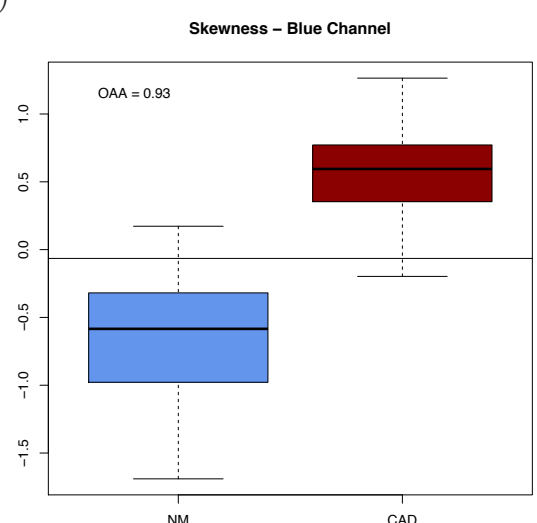

d)

\begin{tabular}{lccc}
\hline Parameter & \multicolumn{3}{c}{ Overall Accuracy } \\
& Red & Green & Blue \\
\hline Mean & 0.74 & 0.84 & 0.84 \\
Mode & 0.73 & 0.80 & 0.89 \\
Skewness & 0.68 & 0.80 & $\mathbf{0 . 9 3}$ \\
Kurtosis & 0.53 & 0.78 & 0.52 \\
\hline \multicolumn{4}{c}{} \\
\hline Parameter & \multicolumn{4}{c}{ Overall Accuracy } \\
& Gray & Satur. & Brightn. \\
\hline Mean & 0.83 & 0.83 & 0.84 \\
Mode & 0.90 & 0.86 & 0.78 \\
Skewness & 0.76 & 0.71 & 0.90 \\
Kurtosis & 0.62 & 0.71 & 0.50 \\
\hline
\end{tabular}

in non-serrated and serrated lumina. Values greater than 0.87 are classified as "non-serrated crypts", values less than 0.87 as "serrated crypts". The majority of crypt lumina that are non-serrated occur in the class CAD. Also HP shows a high amount of non-serrated crypts, but only in the basal part. This confirms the observation that in HP serration is more pronounced in the upper half of the crypt $[2,5]$. Comparing the two classes SSA and SSAD it is seen that the degree of serration declines from SSA to SSAD validating the observation that serration diminishes when cytological dysplasia is pronounced in SSA. TSA shows very low values of solidity confirming the process of hyperserration [2]. 
Fig. 3. Results of Data Set II. Left Boxplots showing values of solidity, classes CAD, HP, SSA, SSAD, TSA, further subdivided into crypts at base (=X_b) and at surface (=X_s). Right Classification assignment using previously computed cut-off.

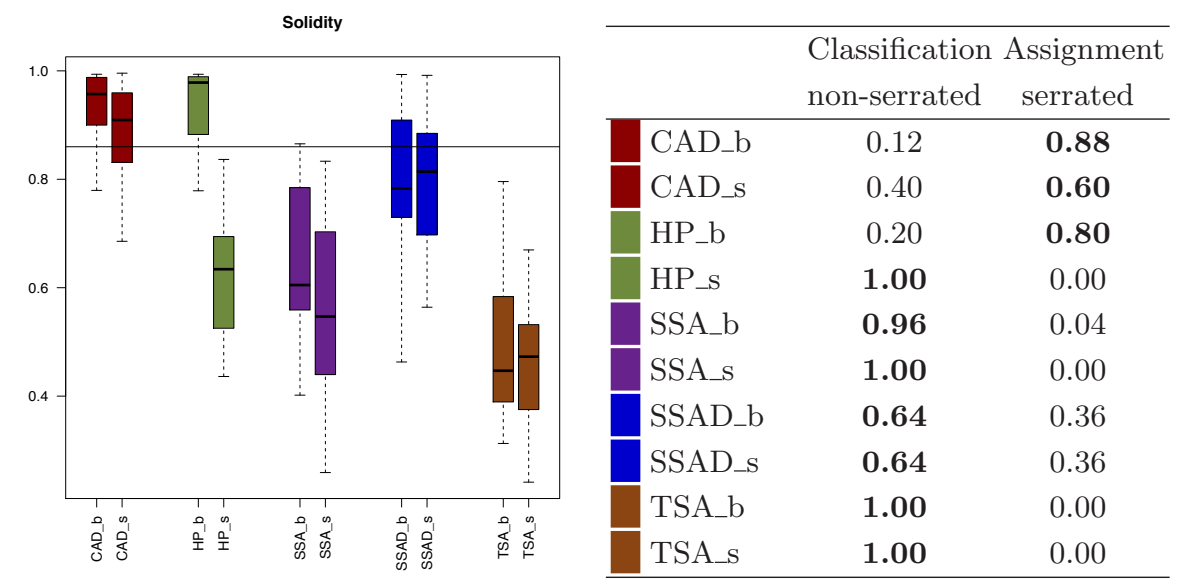

In this study, we evaluated and demonstrated which features are applicable for an automated characterization and classification of colorectal polyps on digitized histological slides. This approach can be integrated in the larger context of computer-aided pre-screening and classification which is increasingly important since colonoscopy screening is a worldwide and frequently applied procedure. Furthermore, processes such as the loss of serration or change in distribution of serration can be measured reproducibly and precisely with the previously mentioned features confirming processes already mentioned in literature and being essential for understanding underlying mechanisms in precursor lesions.

"The present work was performed in fulfillment of the requirements for obtaining the degree "Dr.med." "

\section{References}

1. Hamilton PW, Bankhead P, Wang Y, Hutchinson R, Kieran D, McArt DG, et al. Digital pathology and image analysis in tissue biomarker research. Methods. 2014;70(1):59-73.

2. Bosman FT, Carneiro F, Hruban RH, Theise ND, et al. WHO classification of tumours of the digestive system. Ed. 4. World Health Organization; 2010.

3. Rau T, Agaimy A, Gehoff A, Geppert C, Jung K, Knobloch K, et al. Defined morphological criteria allow reliable diagnosis of colorectal serrated polyps and predict polyp genetics. Virchows Archiv. 2014;464(6):663-672.

4. Jain R, Kasturi R, Schunck BG. Machine vision. vol. 5. McGraw-Hill NY; 1995.

5. Rex DK, Ahnen DJ, Baron JA, Batts KP, Burke CA, Burt RW, et al. Serrated lesions of the colorectum: review and recommendations from an expert panel. The American journal of gastroenterology. 2012;107(9):1315-1329. 


\section{List of publications}

C. Dach, T. Rau, C. Geppert, A. Hartmann, T. Wittenberg, C. Münzenmayer, "Towards computerassisted diagnosis of precursor colorectal lesions" Bildverarbeitung für die Medizin, pp. 266-271, 2016. Springer-Verlag Berlin Heidelberg.

C. Dach, D. Erpenbeck, T. Rademacher, A. Reimann, T. Wittenberg, C. Münzenmayer, M. Benz "Assessment of the plant health status based on hyperspectral and color image analysis towards the cGMP-compliant large-scale production of biopharmaceuticals in plant. " Biomedical Engineering / Biomedizinische Technik Vol. 59, pp. 563-566, 2014 (Journal Article, Conference Paper)

C. Dach, S. Friedl, M. Vieth, M. Benz, C. Münzenmayer, A. Hartmann, C. Geppert, T. Wittenberg, "CAD4GERD - computer-assisted diagnostic for gastroesophageal reflux disease. First results. " in GMDS, Abstractband, 58. Jahrestagung der Deutschen Gesellschaft für Medizinische Informatik, Biometrie und Epidemiologie, 2013 (Abstract)

C. Dach, S. Friedl, M. Vieth, M. Benz, C. Münzenmayer, A. Hartmann, C. Geppert, T. Wittenberg, "Computer-Assistierte Histologie für die Diagnose von Barrett-Ösophagus - eine Pilotstudie", in Endoskopie Heute, Vol. 25, München, 2012, Thieme (Abstract)

C. Dach, C. Held, J. Wenzel, S. Gerlach, R. Lang, R. Palmisano, T. Wittenberg, "Evaluation of an interactive cell segmentation for fluorescence microscopy based on the Graph Cut algorithm. " MIAAB, Microscopic Image Analysis with Applications in Biology, 2011 (Conference Paper)

C. Dach, C. Held, R. Palmisano, T. Wittenberg, S. Friedl, "Evaluation of input modalities for the interactive image segmentation of fluorescent micrographs." Biomedical Engineering/ Biomedizinische Technik, 2011 (Journal Article, Conference Paper)

J. Hill, C. Dach, G. Del Barrio, M. Stellmes, U. Helldén, C. Wang, "Intergating MODIS-EVI and Gridded Rainfall/temperature field for assessing land degradataion dynamics in Horquin sandy lands, Inner Mongolia (China)" Reuter, R. (ed.): $30^{\text {th }}$ EARSeL Symposium - Remote Sensing for Science, Education and Natural and Cultural Heritage, UNESCO, Paris (France), 31 May - 3 June, 2010. (Conference Paper)

A. Ihlow. C. Held, C. Rothaug, C. Dach, T. Wittenberg, D. Steckhan, "Evaluation of Expectation Maximization for the Segmentation of Cervical Cell Nuclei." Bildverarbeitung für die Medizin, pp. 139-143, 2011. Springer-Verlag Berlin Heidelberg.

H. Neumann, C. Dach, T. Wittenberg, C. Münzenmayer, M. Vieth, M. F. Neurath, J. Mudter, "Digital postprocessing enables high quality image enhancement of probe based confocal laser endomicroscopy ( $p C L E$ ) - development of a new technique" 19th United European Gastroenterology Week (UEGW), Congress, October 2010, Barcelona (Spain) 


\section{Talks}

2nd Annual Retreat, September 2010, Erlangen School of Molecular Communication, Kloster Banz, Bad Staffelstein

Talk: "Interactive cell image-segmentation for fluorescence-microscopy based on the GraphCuts algorithm"

EARSeL (European Association of Remote Sensing Laboratories), $3^{\text {rd }}$ Workshop of the Special Interest Group on Remote Sensing of Land Use and Land Cover, November 2009, Bonn

Talk of my diploma thesis: "Using MODIS-EVI time series for assessing land degradation dynamics in Horqin Sandy Lands, Inner Mongolia (China) based on the use of hydrological ratios" 